\title{
Recent Advances and Disputes About Curcumin in Retinal Diseases
}

\author{
Marcella Nebbioso $\mathbb{D}^{1, *}$ \\ Federica Franzone $\mathbb{D}^{1, *}$ \\ Antonio Greco' \\ Magda Gharbiya \\ Vincenza Bonfiglio ${ }^{2}$ \\ Antonella Polimeni ${ }^{3}$ \\ 'Department of Sense Organs, Sapienza \\ University of Rome, Rome, 00185, Italy; \\ ${ }^{2}$ Department of Experimental \\ Biomedicine and Clinical Neuroscience, \\ Ophthalmology Section, University of \\ Palermo, Palermo, 90133, Italy; \\ ${ }^{3}$ Department of Oral and Maxillofacial \\ Sciences, Sapienza University of Rome, \\ Rome, 00185, Italy
}

*These authors contributed equally to this work
Correspondence: Marcella Nebbioso; Federica Franzone

Department of Sense Organs, Ocular Electrophysiology Centre, Umberto

I Policlinic, Sapienza University of Rome, Viale del Policlinico 155, Rome, 0016I,

Italy

Tel $+39 / 06 / 49975422$

Fax $+39 / 06 / 49975426$

Email marcella.nebbioso@uniromal.it; federica.franzone9l@gmail.com

\begin{abstract}
Curcumin belongs to the group of so-called phytocompounds, biologically active molecules produced by plants exerting a beneficial effect on health. Curcumin shows a wide spectrum of different properties, being an anti-inflammatory, antioxidant, antimicrobial and antimutagenic molecule. The purpose of the review is to examine what literature reported on the characteristics of curcumin, particularly, on the beneficial and controversial aspects of this molecule, aiming for a better therapeutic management of retinal diseases. The retina is a constant target of oxidative stress, this tissue being characterized by cells rich in mitochondria and by vessels and being, obviously, continuously reached from photons affecting its layers. Particularly, the retinal ganglion cells and the photoreceptors are extremely sensitive to oxidative stress damage and it is well known that an imbalance in reactive oxygen species is often involved in several retinal diseases, such as uveitis, age-related macular degeneration, diabetic retinopathy, central serous chorioretinopathy, macular edema, retinal ischemiareperfusion injury, proliferative vitreoretinopathy, hereditary tapeto-retinal degenerations, and retinal and choroidal tumors. To date, several studies suggest that oral treatment with curcumin is generally well tolerated in humans and, in addition, it seems to have no negative effects: therefore, curcumin is a promising candidate as a retinal disease therapy. Unfortunately, the primary limitation of curcumin is represented by its poor bioavailability, in fact only a minimal fraction of this substance can reach the blood stream in the form of a biologically active compound. However, many steps have been made in several fields. In the future, it is expected that the strategies developed until now to allow curcumin to reach the target tissues in adequate concentrations could be ameliorated and, above all, large in vivo studies on humans are needed to demonstrate the total safety of these compounds and their effectiveness in different eye diseases.
\end{abstract}

Keywords: anti-inflammatory proprieties, antioxidant proprieties, exosomes, miRNA, nanosphere, natural compounds

\section{Introduction}

Curcumin (IUPAC name is 1,7-bis[4-hydroxy-3-methoxyphenyl]-1,6-heptadiene3,5-dione), also known as Diferuloylmethane, Natural Yellow 3 or E100, according with the European coding of food additives, ${ }^{1}$ it is a herbal agent appearing as a yellow-orange colored pigment, a peculiarity that it shares with ginger. ${ }^{2,3}$

It is the main polyphenolic agent derived from the Curcuma longa plant (turmeric) and one of the most widely studied natural products in recent years, due to its therapeutic properties. ${ }^{4,5}$

For hundreds of years, curcumin has been extensively used as a medical herb in traditional Chinese ${ }^{6}$ and Ayurvedic medicine, ${ }^{7}$ being an essential element of various 
natural remedies for the treatment of several pathologies such as atherosclerosis, diabetes, liver disease, rheumatism, and infectious and oncological diseases. ${ }^{8}$ Curcumin demonstrated a wide spectrum of different properties, especially being an anti-inflammatory, ${ }^{9,10}$ anti-oxidant, antimicrobial and antimutagenic molecule. ${ }^{11,12}$ Nevertheless, it is necessary to emphasize that its biomedical potential is limited because of its poor digestive bioavailability. In fact absorption is low, while metabolism and elimination are extremely rapid. ${ }^{13,14}$ This topic will be discussed later, in the appropriate section. Furthermore, curcumin is used in cookery as a spice, in the cosmetic industry and in fabric dying as a coloring agent. ${ }^{15}$

In ophthalmology, curcumin was initially used as eye drops in patients affected by conjunctivitis, demonstrating the same efficacy of soframycin, ${ }^{16}$ then, in 1996, Awasthi et al reported its ability in prevention of cataractogenesis in rats, treated ex vivo with curcumin $(75 \mathrm{mg} / \mathrm{kg}$ P.O. for 14 days). ${ }^{17}$

Subsequently, curcumin was administered at a dose of $375 \mathrm{mg}$ three times per day for 12 weeks, as treatment of complicated chronic anterior uveitis cases, showing an amelioration of symptoms. ${ }^{18}$ In the last decade, researchers used this natural remedy in multiple ophthalmology disorders, especially in diabetic retinopathy (DR), glaucoma and age-related macular degeneration (AMD), seeing this molecule as a potential candidate for the prevention and treatment of degenerative and inflammatory eye diseases. ${ }^{19}$

This review aims to evaluate what literature reported regarding the peculiarities of curcumin, specifically focusing on the beneficial and controversial aspects of this substance, in order to identify its application in the therapeutic management of retinal diseases.

\section{The Chemical Structure of Curcumin}

Curcumin, normally classified as a natural polyphenol, shows different functional groups: the aromatic ring systems or methoxylated phenols are linked by two a,b-unsaturated carbonyl groups (Figure 1). Generally, curcumin exists in two tautomeric forms, the keto-enol and di-keto tautomers. The keto-enol tautomer is the predominant form when curcumin is present in polar organic solvents. Its chemical formula is $\mathrm{C}_{21} \mathrm{H}_{20} \mathrm{O}_{6}(\mathrm{MW} 368.38 \mathrm{~g} / \mathrm{mol})^{1}$ and it tends to appear solid at room temperature with a melting point of $183{ }^{\circ} \mathrm{C} .^{4}$ Vogel extracted it more than

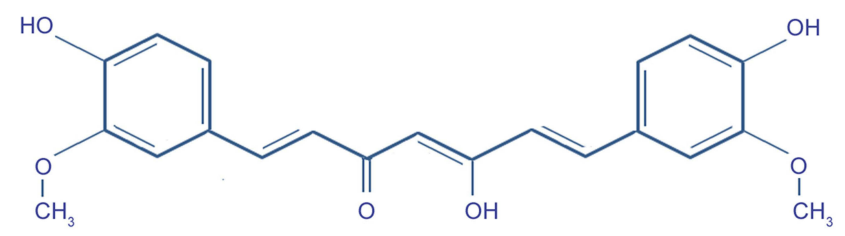

Figure I Chemical structure of the curcumin.

140 years ago, in 1815, from the dried rhizome of the traditional Indian herb Curcuma longa, a perennial plant belonging to the Zinziberacee family and also known as Indian saffron or turmeric. Lampe subsequently synthesized it, in $1913 .^{20}$ The turmeric rhizome is composed of curcuminoids (3-5\%) and a volatile fraction $(2-7 \%):^{21,22}$ curcuminoids include cinnamoyl methane derivatives such as curcumin, demethoxicurcumin (DMC) and bisdemethoxicurcumin (BDMC), while the volatile fraction mainly contains characteristical terpene compounds, such as zingiberene, curcumol and $\beta$-turmerone. ${ }^{5}$

DMC and BDMC demonstrated similar biological properties to curcumin, being able to suppress the activity of enzymes such as COX-2, responsible for NF-kB activation. ${ }^{23}$

All the metabolites of curcumin, as well as hexahydrocurcumin (HHC), octahydrocurcumin (OHC), dihydrocurcumin and tetrahydrocurcumin (THC), show both anti-inflammatory and anti-oxidant effects. ${ }^{24}$

The Curcuma longa's rhizomes represent the most useful part of the plant: in fact, once the rhizomes are boiled and dried in the sun, they are crushed in order to produce a yellow-orange powder, whose biological active component is curcumin. ${ }^{25}$

Owing to its biochemical properties, curcumin belongs to the group of so-called phytocompounds, biologically active molecules produced by plants exerting a beneficial effect on health. Other kinds of phytocompounds are betacarotene, lycopene, quercetin and epigallocatechin gallate. ${ }^{26}$

\section{Biochemical Properties of Curcumin}

\section{Curcumin Anti-Inflammatory Properties}

Inflammation is considered a physiological phenomenon generally occurring as a consequence of different pathological events: it is recognized as a sort of human body protective mechanism emerging when injuries appear, with the risk of damaging the organism.

Curcumin is able to block numerous and different pathways normally activated by the inflammation process: for instance, curcumin exerts a significant inhibitory effect on 
cyclooxygenase-2 (COX-2), as well as inhibits the PGE2 synthase 1, responsible for prostaglandin E2 (PGE2) synthesis, and 5-lipoxygenase (5-LOX). In addition curcumin determines $\mathrm{I} \kappa \mathrm{B} \alpha$ gene expression reduction and modulates the nuclear factor $-\kappa \mathrm{B}(\mathrm{NF}-\kappa \mathrm{B})$ and activator protein-1 (AP-1) expression. The latter two are both transcriptional factor genes, which control several cellular activities: more in detail, NF- $\kappa \mathrm{B}$ is a trigger of inflammation, immune activity and cell proliferation, whereas AP-1 stimulates cell proliferation. NF- $\kappa \mathrm{B}$ mediates inflammation through cyclooxygenase-2 (COX-2), lipoxygenase (5-LOX), and xanthine oxidase activation. Furthermore, NF- $\kappa \mathrm{B}$, along with AP-1, which is also overexpressed in cancer cells, induces the expression of inducible nitric oxide synthase (iNOS), enhancing the production of nitric oxide (NO), tumor necrosis factor (TNF)- $\alpha$, and prostaglandins.

All of these proinflammatory factors lead to vascular endothelial growth factor (VEGF) expression: thus, as a consequence, VEGF triggers endothelial proliferation with angiogenesis and extracellular matrix (ECM) degradation caused by matrix metalloproteinases (MMPs) activation. ${ }^{4}$

In addition to this, curcumin downregulates janus kinase, signal transducer and activator of transcription (JAK/STAT) pathway determining, as a consequence, a TNF- $\alpha$ and proinflammatory interleukins (IL-1, IL-2, IL-6, IL-8 and IL-12) deregulation. Among these cytokines, IL-8, which induces severe inflammatory reactions, is particularly inhibited by curcumin. Gupta et al even demonstrated the curcumin's ability to inhibit p300/ CREB-specific acetyltransferase, which normally prevents histone/non-histone proteins acetylation causing TNF- $\alpha$ levels reduction. $^{27}$ Moreover, curcumin modulates IkB kinase activity with consecutive NF- $\kappa \beta$ downregulation. ${ }^{28}$

Other studies suggest that curcumin can regulate gene transcription, also via the peroxisome proliferatoractivated receptor- $\gamma$ (PPAR- $\gamma$ ) activation. PPAR- $\gamma$, by binding the peroxisome proliferator response element (PPRE) in the promoter sequence of genes, exerts an antiinflammatory effect (Scheme 1). ${ }^{5}$

\section{Curcumin Anti-Oxidant Properties}

Nowadays, oxidative stress is defined as an imbalance between reactive oxygen species (ROS) and antioxidant defenses. $^{29}$ ROS, a normal product of a cell's metabolism, may be either beneficial or harmful for the cell, depending on their concentration: indeed, low levels of ROS are crucial in cell proliferation induction, intracellular signal transduction and apoptosis, but high concentrations of oxidative reactive species can interfere with normal biological pathways of the cell. ${ }^{15}$ Specifically, ROS levels are the result of two mechanisms: endogenous ROS formation and exposure to exogenous ROS. Endogenous ROS are the product of mitochondrial oxidative process and some

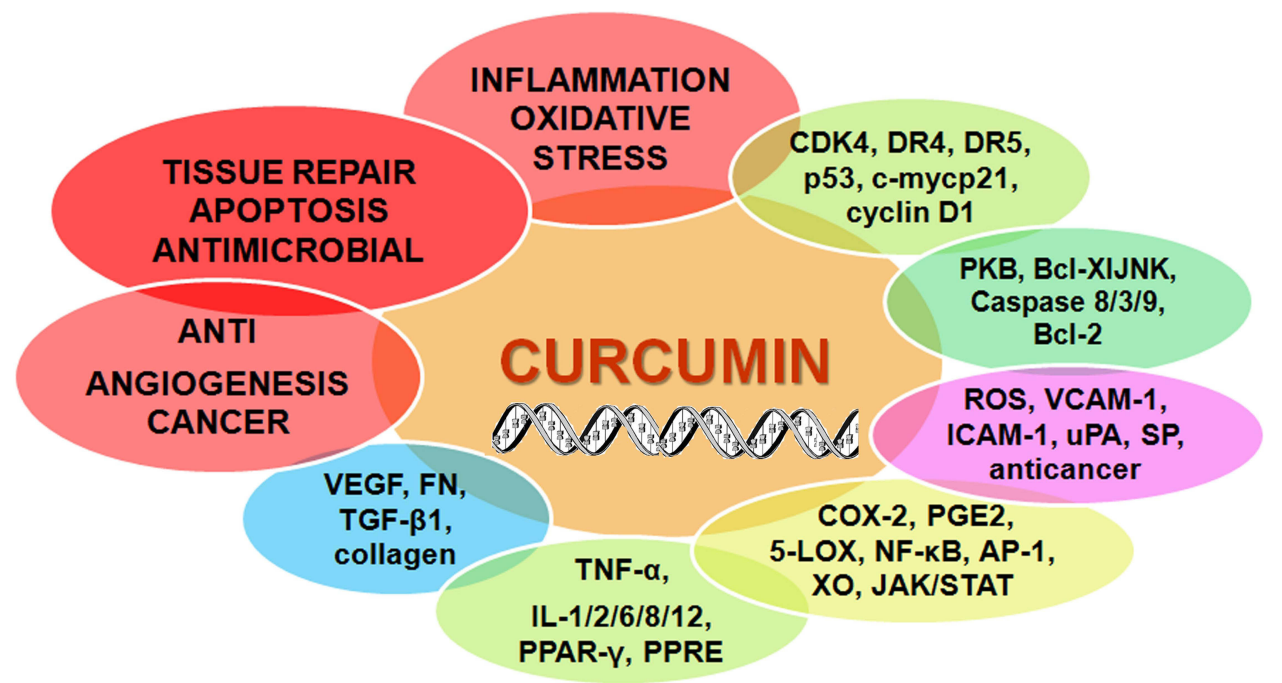

Scheme I Pathways for ocular disease and biochemical properties of curcumin. Proliferation pathway: CDK4, cyclin DI, c-myc; cell survival pathway: Bcl-2, Bcl-xL; caspase activation pathway: caspase 8/3/9; molecular pathways containing the protein kinase c-Jun N-terminal kinases: JNK; protein kinase B: PKB; reactive oxygen species: ROS; endothelial vascular cell adhesion molecule-I: VCAM-I; intracellular adhesion molecule-I: ICAM-I; leukocyte adhesion molecule-I: ELAM-I; metalloproteinases: MMP; serine protease family: SP; urokinase plasminogen activator system: uPA; tumor suppressor pathway: p53, p2I; death receptor pathway: DR4, DR5; cyclooxygenase-2: COX-

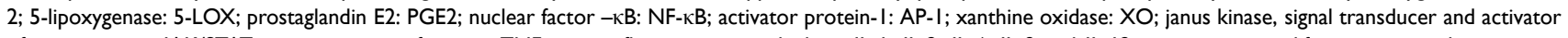
of transcription: JAK/STAT; tumor necrosis factor- $\alpha$ : TNF- $\alpha$; proinflammatory interleukins: IL-I, IL-2, IL-6, IL-8 and IL-I2; peroxisome proliferator-activated receptor- $\gamma$ : PPAR- $\gamma$; vascular endothelial growth factor: VEGF; transforming growth factor: TGF- $\beta$ I; stimulate the fibroblasts expression of fibronectin: FN; collagen. 
enzymatic reactions catalyzed by some oxidoreductase enzymes. $^{30}$

A situation of persistent oxidative stress, commonly observed in some neurodegenerative, ${ }^{31}$ cardiovascular, endocrine, oncological and autoimmune diseases, ${ }^{32}$ is able to activate plenty of inflammation molecular signaling pathways.

ROS are able to modulate both the nuclear factor- $\kappa \beta$ $(\mathrm{NF}-\kappa \beta)$ and tumor necrosis factor alpha (TNF- $\alpha$ ) pathways, which are usually involved in the inflammatory cascade. $^{29}$

In 2015 Deogade and Ghate ${ }^{6}$ highlighted curcumin's anti-inflammatory and antioxidant effectiveness, probably attributable to its hydroxyl and methoxy groups: for instance, this phytocompound and its derivatives are able to block lipid peroxidation by the use of a polyunsaturated fatty acid called linoleate, in addition to their action as ROS and NO scavengers. ${ }^{4}$

Most natural antioxidant substances show a phenolic or a $\beta$-diketone group. In light of the presence of both phenolic and $\beta$-diketone functional groups on the same molecule, curcumin and its analogs are considered as unique molecules. ${ }^{33}$

Particularly, the phenolic group seems to be responsible for the antioxidant properties of any plant phenolic compound. Therefore, some authors studied the properties of curcumin focusing precisely on its phenolic rings, ${ }^{33,34}$ while others have instead sustained that the antioxidant role would be played rather by the $\beta$-diketone fraction of curcumin and its derivatives. $^{21,35}$

In the context of this debate, of great interest are the results obtained by Jovanovic et al who deeply examined curcumin radical's physicochemical properties by laser flash photolysis and pulse radiolysis. In order to investigate the role of phenol hydroxy and $\beta$-diketone moieties and to determine the properties of the curcumin radical, they synthesized two methylated curcumin derivatives, methylcurcumin and trimethylcurcumin. The prevalent curcumin radical is represented by the phenoxyl, which is obtained either by an intramolecular $\mathrm{H}$-atom transfer from any methoxyphenol ring to the $\beta$-oxo-alkyl radical or by a direct one-electron oxidation of a methoxyphenol group. In light of their results, the authors concluded that the $\beta$-diketone moiety alone does not possess antioxidant properties and that both $\beta$-diketone and phenol are necessary for curcumin's antioxidant properties. ${ }^{36}$

However, regarding antioxidant properties, not all authors agree that curcumin is an excellent anti-oxidant:
Litwinienko et al emphasize that, since curcumin is a (bis) phenol, it can trap lipid peroxyl 5,6 and 1,1-diphenyl2-picrylhydrazyl 7 radicals by releasing one of its phenolic $\mathrm{H}$-atoms, but this ability does not make it an antioxidant molecule. $^{37}$

Moreover, they affirm that, unlike what was observed by Jovanovic et $\mathrm{al}^{36}$ in ionizing solvents radical formation, it does not result as a "rapid intramolecular H-shift", but it occurs after a proton loss. According to Litwinienko et al, this finding would resolve the $\mathrm{CU}$ antioxidant controversy. ${ }^{37}$

\section{Curcumin Angiogenic Properties}

ROS seem to play an essential role in the angiogenic homeostasis modulation and their effect is mainly due to their concentration: as already stated, high ROS doses induce oxidative stress, with subsequent angiogenesis inhibition, whereas low doses of ROS (mainly $\mathrm{H}_{2} \mathrm{O}_{2}$ ) stimulate angiogenesis. ${ }^{33,38}$

Several studies revealed that curcumin inhibits angiogenesis via different mechanisms: Chen et al highlighted the ability of curcumin to determine the suppression of isoforms 165 and 121 of VEGF secretion in U937 and Raji cells. ${ }^{39}$ Millanta et al observed the angiogenesis suppression by curcumin, measured as network formation of endothelial cells on Matrigel. The same phenomenon was detected in the endothelial cell line - ECV304 cells. ${ }^{40}$ Yoysungnoen et al inoculated HepG2 cells onto the upper layer of the skinfold chamber: these cells, then, were implanted into mice, which were orally fed with curcumin. In this study, the angiogenesis processes were evaluated as tumor neocapillary density, by using a digital image analysis. The tumor angiogenesis resulted in inhibition via VEGF and COX-2 reduction by curcumin $3000 \mathrm{mg} / \mathrm{kg}$ treatment. ${ }^{41}$ Moreover, Li et al discovered a decrease in the NF-KB pathway functioning with liposomal curcumin.

Another mechanism by which curcumin indirectly prevents angiogenesis is that which involves the modulation of cell adhesion molecules, like endothelial vascular cell adhesion molecule-1 (VCAM-1), intracellular adhesion molecule-1 (ICAM-1) and leukocyte adhesion molecule-1 (ELAM-1). Curcumin is also able to decrease the activity of metalloproteinases (MMP), the serine protease family and the urokinase plasminogen activator system (uPA). This peculiar property of curcumin results in endothelial cell migration and transforming growth factor (TGF), 
TNF, hepatocyte growth factor (HGF), and VEGF release inhibition. $^{42}$

In conclusion, all of the properties herein described demonstrate that curcumin may be useful in several angiogenesis-related disorders as eye diseases showing these underlying processes. ${ }^{15}$

\section{Curcumin Anticancer Effects}

Curcumin is a substance characterized by numerous pleiotropic features: as suggested by different in vivo and in vitro studies, it even shows anticancer potential. Particularly, curcumin inhibits carcinogenesis at three distinct stages: angiogenesis, tumor promotion and growth. It can modulate several signaling pathways, especially the tumor suppressor pathway (p53, p21), the death receptor pathway (DR4, DR5), the proliferation pathway (CDK4, cyclin D1, c-myc), the cell survival pathway (Bcl-2, Bcl-xL) and the caspase activation pathway (caspase 8, 3 and 9), also including a molecular pathway containing the protein kinase c-Jun N-terminal kinases (JNK) and the protein kinase $\mathrm{B}$ (PKB). ${ }^{43,44}$ Devassy et al reported the curcumin ability of preventing several cancer types including breast, lung, colon and pancreas tumors, in addition to multiple myeloma. ${ }^{45}$

\section{Curcumin Wound Healing Effects}

In addition to the features previously described, no less important is the ability of curcumin to enhance tissue repair processes: wound healing is a complex condition which includes inflammatory processes associated to granulation and tissue remodeling. ${ }^{44}$

Several growth factors and cytokines are involved: first of all the transforming growth factor (TGF- $\beta 1$ ), which plays a key role in the wound healing mechanism by stimulating the fibroblasts expression of fibronectin (FN) and collagen. ${ }^{46}$

\section{Curcumin and Retinal Diseases}

The retina is the structure that, occupying the posterior segment of the ocular globe, is directly in touch with the vitreous humor and it is considered a part of the central nervous system (CNS). It is composed of several cell types and, more in detail, two kinds of photoreceptors can be described: the rods, more located at the retina's periphery, function in scotopic light conditions $(<0.1$ lux, night vision) and are particularly sensitive to darkness, while the cones, more concentrated in the macula lutea, are deeply sensitive to the fine shape and to the light, being able to discriminate colors and to work in photopic light conditions ( $>10$ lux). In addition to the photoreceptors, retinal ganglion cells (RGCs), bipolar cells, amacrine cells, horizontal cells, Müller cells and retinal pigment epithelial cells (RPEC) are also present in the retina. The RPE is a retinal layer which performs many crucial functions, such as the digestion of damaged photoreceptor outer segments (POS) and the maintaining of retinal structure. Munia et al evaluated the effects of resveratrol, lutein and curcumin on human retinal epithelial cells, demonstrating that these cells, after an oxidative stress insult, were protected from death by a pre-treatment with these nutraceutical compounds. ${ }^{47}$

The retina is a constant target of oxidative stress being characterized by cells rich in mitochondria and by vessels and, obviously, being continuously reached from photons of light affecting its layers.

This situation explains why most of the retinal pathological processes involve oxidative stress imbalance with plenty of ROS and reduced levels of antioxidant scavengers.

Moreover, it is crucial to highlight that, generally, the retina shows a high content of polyunsaturated fatty acids (PUFA) and, in particular, as aforementioned, a higher oxygen and glucose uptake has been observed, in comparison with other tissues; these characteristics make the retina strongly prone to oxidative stress.

Particularly, the RGCs and the photoreceptors are extremely sensitive to oxidative stress damage and it is well known that ROS imbalance is often involved in several retinal diseases, such as uveitis, age-related macular degeneration (AMD), diabetic retinopathy (DR), central serous chorioretinopathy (CSC), macular edema (ME), and from uncommon etiologies, retinal ischemiareperfusion injury (RIRI), retinal and choroidal tumors, proliferative vitreoretinopathy (PVR), hereditary tapetoretinal degenerations, and retinal and choroidal tumors. ${ }^{1}$

\section{Uveitis and Curcumin}

As previously stated, in ophthalmology one of the first employments of curcumin was in the field of uveitis: Lal et al studied its clinical application in the therapy of chronic anterior uveitis (CAU). Patients enrolled were divided into two groups depending on the severity of the manifestations: one group received curcumin alone, while the other also received antitubercular treatment. Curcumin was administered in the form of capsules (one capsule three times a day) each one containing a dose of $375 \mathrm{mg}$ of the molecule. In conclusion, the authors reported a comparable efficacy between 
curcumin and corticosteroid therapy, the latter one being the only standard treatment recognized for this disease. ${ }^{48}$

Some years later, a long term follow up of oral phospholipidic curcumin (iPhytoone, Indena S.p.A, Milan, Italy or Norflo $^{\circledR}$, Eye Pharma, Genoa, Italy) treatment, in addition to the traditional therapy, was successfully performed in patients with recurrent anterior uveitis (RUA) of different origin: three groups were identified as specifically herpetic, autoimmune and other types of uveitis. This study highlighted curcumin's anti-inflammatory properties and, in addition, its good efficacy in preventing any RUA relapses. ${ }^{49}$

Recently, an oral phospholipidic curcumin approach was also attempted in patients with juvenile idiopathic arthritis-associated uveitis with promising results in reducing chronic anterior chamber flare. ${ }^{50}$

\section{Age-Related Macular Degeneration (AMD)}

The protective role of curcumin has been also investigated in the AMD (Figure 2), where Mandal et al observed a modulation in the inflammatory genes expression in the retinas of curcumin fed Wistar rats (2000 ppm). The NF$\mathrm{kB}$ result was inhibited and they also revealed an early growth response protein 1 (EGR1) and intercellular adhesion molecule 1 (ICAM1) reduction in retinal cell lines 661W and ARPE-19. ${ }^{51}$ Particularly in AMD, Muangnoi et al attempted an approach with a curcumin prodrug called diethyl disuccinate (CurDD), showing that this molecule is more effective in reducing oxidative stress in human ARPE-19 cells when compared to curcumin. ${ }^{52}$

In all cases, CurDD was more effective than its parent drug against oxidative stress-induced damage to ARPE-19 cells. These findings highlight CurDD as a more potent drug compared to curcumin (Cur) against oxidative stress and indicates that its protective effects are exerted through modulation of key apoptotic and antioxidant molecular pathways. $^{52}$

\section{Diabetic Retinopathy (DR)}

Diabetic retinopathy (DR) is a metabolic and chronic inflammatory disorder, mainly characterized by ischemia, microaneurysms, hemorrhages, retinal edema, neovascularization and neuronal degeneration. ${ }^{53}$ It is considered a microvascular retinal disease which comprises two different phases: one early and typically non-proliferative stage (non-proliferative diabetic retinopathy or NPDR)
IR $30^{\circ} \mathrm{ART}+\mathrm{OCT} 20^{\circ}$ (5.6 mm) ART (9) Q: 28 [HS]

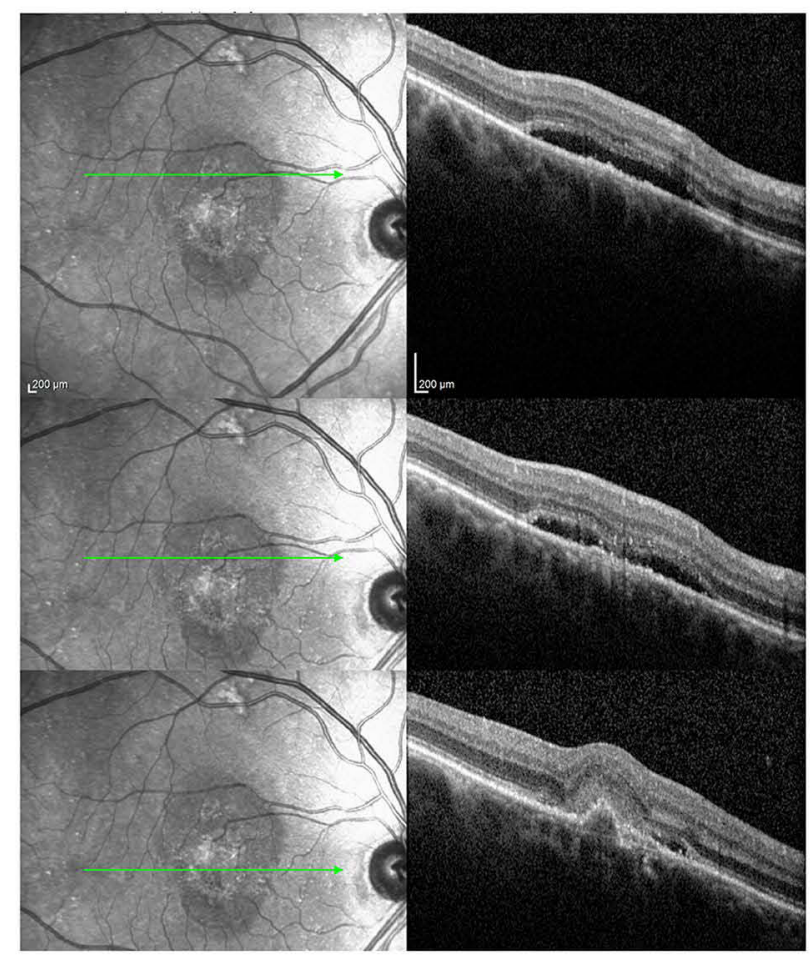

IR $30^{\circ}$ ART [HR]
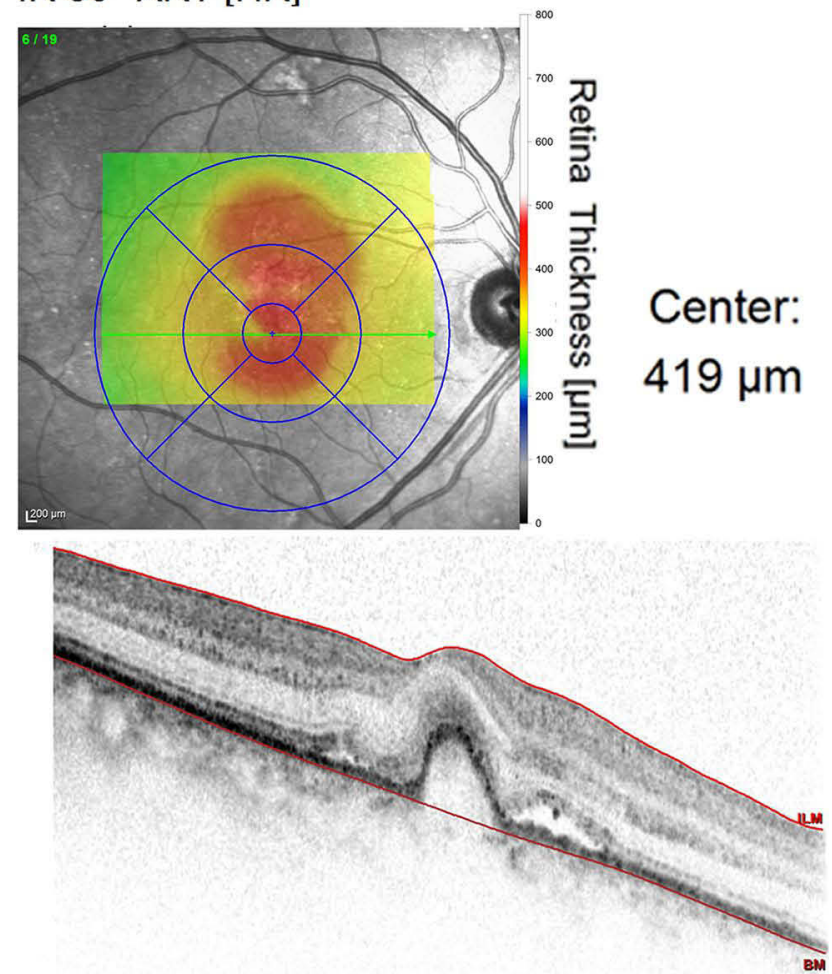

Figure 2 Spectral domain-optical coherence tomography of a right eye affected by age-related macular degeneration (AMD). Macular neuroepthelial detachment (central thickness of $419 \mu \mathrm{m})$ and choroidal neovascular membrane (CNV). 
and a later one, more serious and characterized by blood vessel proliferation (proliferative diabetic retinopathy or PDR). ${ }^{54}$

Therefore, these latter structures are the more afflicted by the DR progression in addition to the photoreceptors. It has been recognized that several metabolic pathways are involved when the ROS imbalance is present: advanced glycation end product (AGE) pathway, polyol pathway, protein kinase $\mathrm{C}(\mathrm{PCK})$ and hexosamine pathway. ${ }^{55}$

Particularly, the AGE accumulation determines a massive release of ROS, which cross-links proteins with consecutive vascular and extravascular structure alterations (Figure 3).

Moreover, the nuclear enzyme poly(ADP-ribose) polymerase (PARP) activation after an oxidative insult in PARP-/- mice and diabetic rats has been detected by Chiu et al. In addition to this, they observed NF-kB and endothelin-1 (ET-1) activation. ${ }^{56}$ Furthermore, vascular endothelial growth factor (VEGF), one of the main angiogenic factors implicated in ocular neovascularization as a consequence of ischemia, increases in DR eyes. ${ }^{57}$

Wang et al found that curcumin determines TNF- $\alpha$ and VEGF reduction with an increase in antioxidant enzymes SOD and catalase levels. ${ }^{58}$ Kumar et al investigated the role of curcumin on streptozotocin-induced diabetic rats: they observed an oxidative stress level reduction and curcumin's ability in maintaining the chaperone function of alpha-crystallin. ${ }^{59}$ Curcumin is also able to inhibit VEGF expression in the retina under hyperglycemic conditions. ${ }^{60}$ Khimmaktong et al observed the processes of retinal regeneration after curcumin treatment and, notably, they reported a normalization in diabetic microvasculature, with a tortuosity, narrowing and micro-aneurysms reduction. ${ }^{61}$ Then, curcumin may downregulate high glucose-induced inflammatory injury in RPEC, modulating the ROS/PI3K/AKT/mTOR signaling pathway. ${ }^{62}$

Curcumin efficacy was also investigated in chronic diabetic ME. Mazzolani et al administered curcuminphospholipid lecithin formulation (iPhytoone ${ }^{\circledR}$ ) as tablets $\left(\right.$ Norflo $^{\circledR}$ ) twice a day. After the treatment, visual acuity results improved along with a reduction in macular edema. ${ }^{63}$

\section{Central Serous Chorioretinopathy (CSC)}

Central serous chorioretinopathy (CSCR) is a well-known retinal disease characterized by a typical retinal serous neurosensory elevation (Figure 4). Usually, the disorder is self-limiting, but, sometimes, a photoreceptor and RPEC damage is recognized. Nowadays, the CSCR pathogenesis is still unclear but choroid permeability alterations are suggested as the main underlying event.

\section{IR $30^{\circ} \mathrm{ART}+\mathrm{OCT} 30.0^{\circ}(8.6 \mathrm{~mm}) \mathrm{ART}$ (10) Q: 14 [HS]}

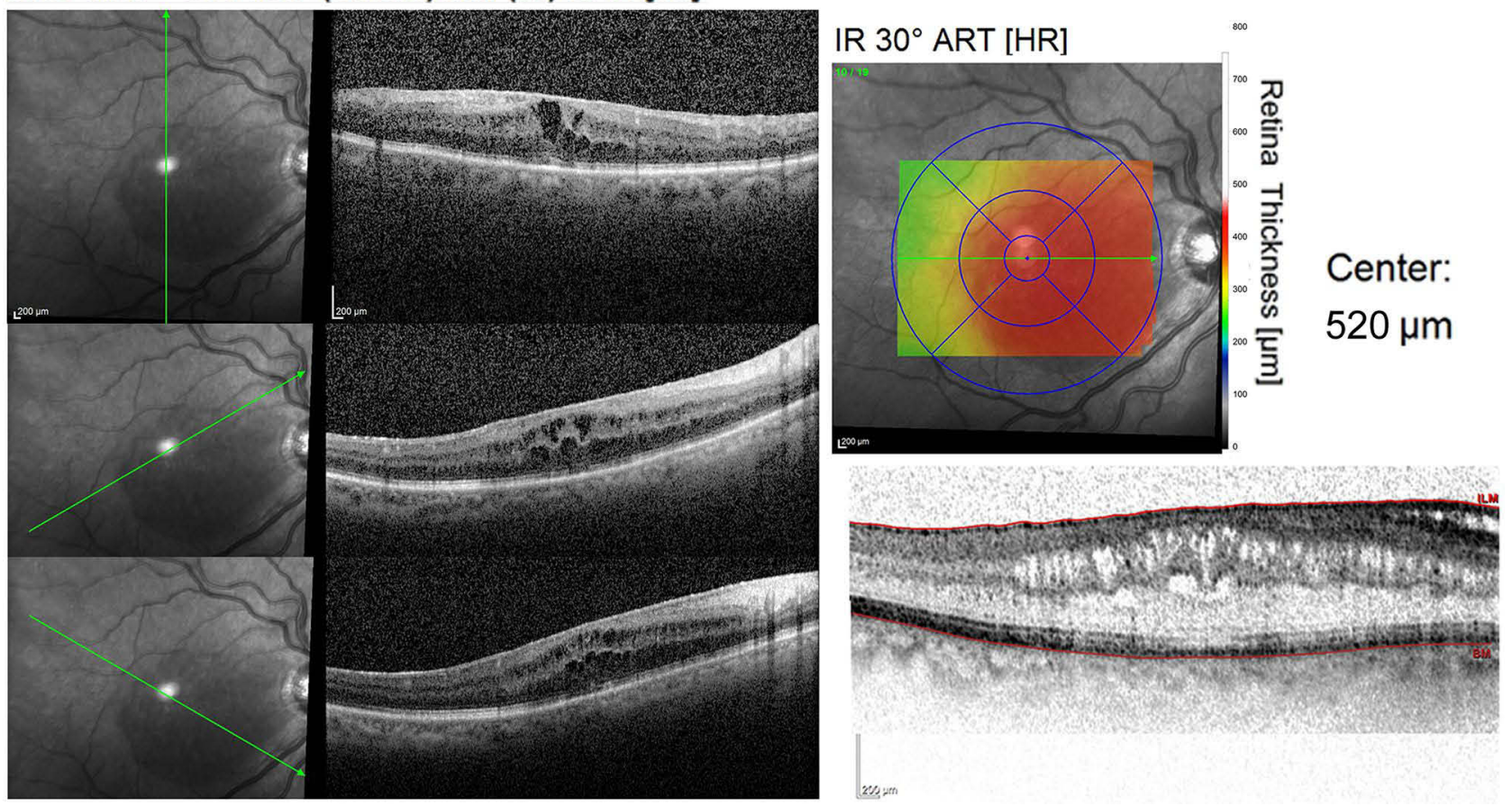

Figure 3 Spectral domain-optical coherence tomography of a right eye affected by diabetic macular edema (ME). Spongy aspect of neuroretin (central thickness of $520 \mu \mathrm{m}$ ) and hyperreflectivity of epiretinal membrane. 
Curcumin administered as tablets (Norflo ${ }^{\circledR}$ ), a curcumin-phospholipid (lecithin) delivery system, was investigated as a potential anti-inflammatory treatment for CSCR in a 12-month follow-up study: all patients showed a significant reversal of visual acuity reduction. Currently, the appropriate therapeutic plan for CSCR management has not yet been planned, however, according to Mazzolani et al the treatment should be considered in CSCR acute cases which do not undergo spontaneous resolution and in chronic cases. ${ }^{63}$

\section{Macular Edema (ME) from Uncommon Etiologies}

The ME, defined as macular fluid accumulation in the intraretinal and/or subretinal layers, is often a common complication of several retinal diseases, such as AMD, DR and retinal vein occlusion (RVO). Nevertheless, sometimes $\mathrm{ME}$ is considered as due to uncommon etiologies such as postoperative ME (Figure 5) or chronic CSC.

A retrospective study evaluated the efficacy and tolerance of a curcumin carrier in this kind of patient. More in detail, subjects showing chronical and symptomatic ME of unknown origin were enrolled and then administered with a polyvinylpyrrolidone-hydrophilic carrier (CHC). The protocol consisted of a loading and a maintaining phase,

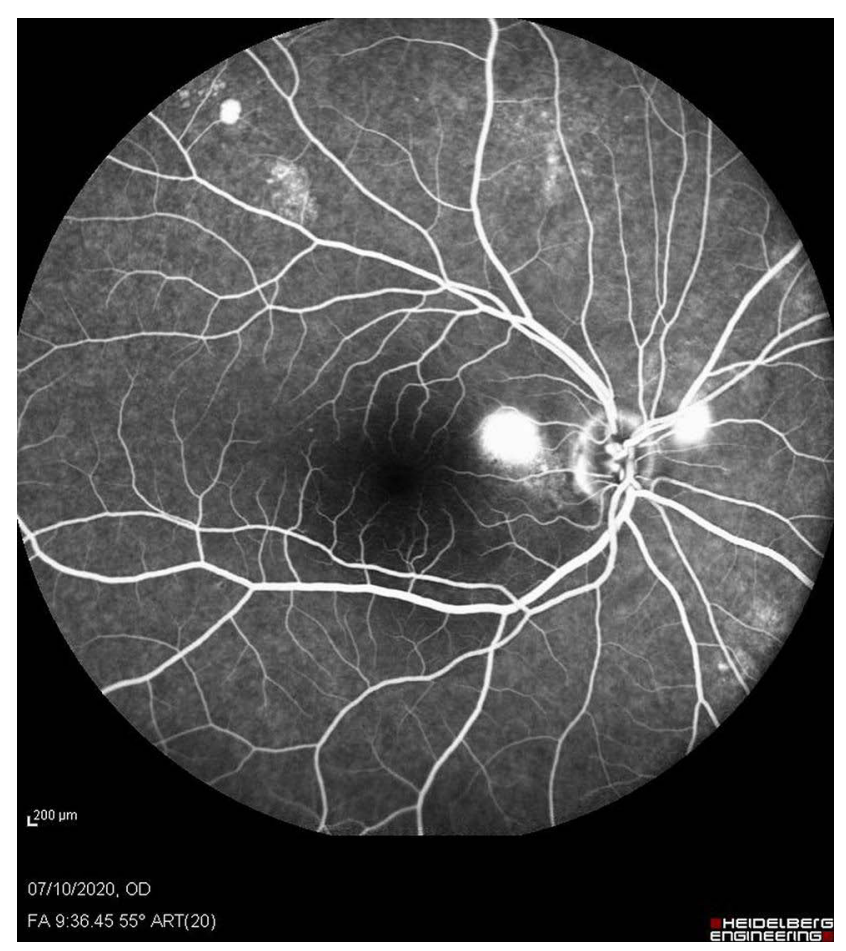

Figure 4 Retinal angiography of a right eye affected by recurrent central serous chorioretinopathy (CSC). thus patients previously received two capsules a day for 1 month and then one capsule every day for the next 2 months. Each CHC capsule consisted of $60 \mathrm{mg}$ of CurcuWIN Dry Powder 20\% (curcuminoids 20-34\%, hydrophilic carrier $60-80 \%$, and natural antioxidants $1-$ $5 \%$ ). In both conditions of $\mathrm{ME}, \mathrm{CHC}$ demonstrated beneficial treatment, so curcumin can be considered a potentially promising treatment in complicated forms of ME. ${ }^{64}$

\section{Retinal Ischemia}

In the case of pathological reperfusion injury after retinal ischemia due to a loss of intraocular perfusion pressure, consequence of ocular hypertension (Figure 6) or intra/postoperative conditions, the protective role of curcumin on retinal neurons was described by Wang et al. They claim that curcumin is capable of inhibiting both the nuclear factor kappa-light-chain-enhancer of activated B cells (NF-kB) and the signal transducer and activator of transcription (STAT3). Therefore, curcumin blocks or reduces, on Wistar rats, the consecutive overexpression of monocyte chemoattractant protein 1 (MCP-1). ${ }^{65}$ Curcumin is also able to downregulate the c-Jun N-terminal kinase (JNK) expression such as observed in retinal neurons and capillaries in stroke spontaneously hypertensive rats (SHR). ${ }^{66}$

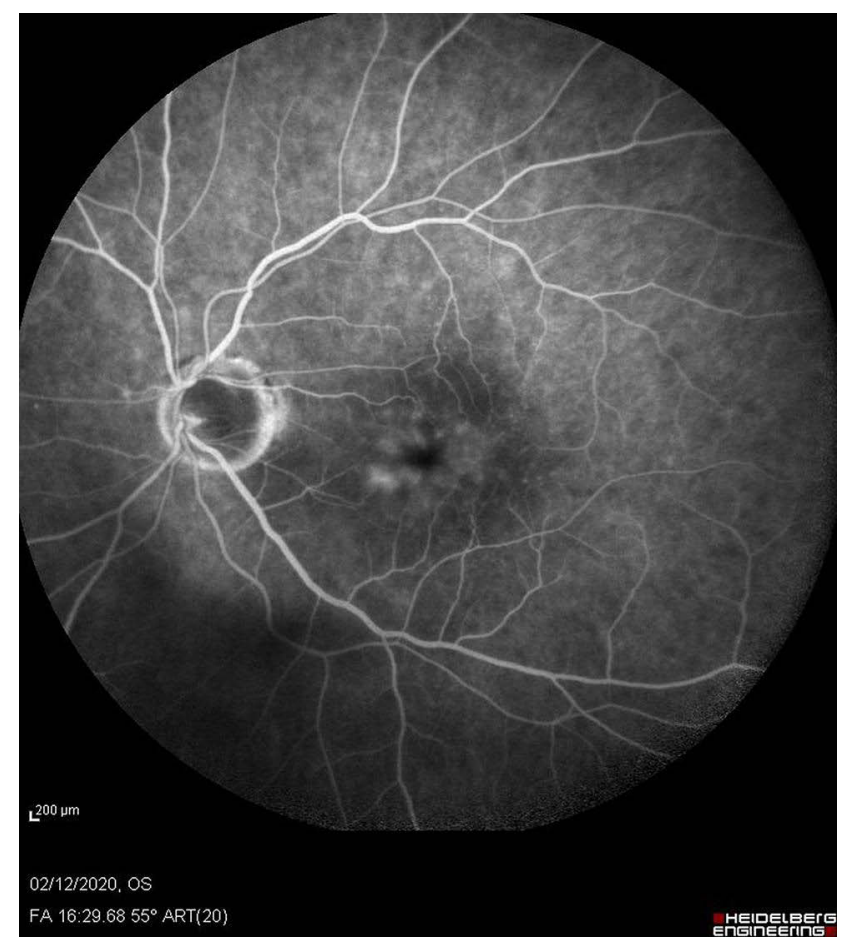

Figure 5 Retinal angiography of a left eye affected by Irvine Gass syndrome. Macular and parapapillary (temporal edge) edema after cataract surgery in a patient suffering from chronic glaucoma with excavated and pale optic disc. 
Furthermore, following retinal ischemia due to central vascular occlusion, or diabetes mellitus, or retinal detachment can arise proliferative vitreoretinopathy (PVR). PVR is sustained by RPEC proliferation and migration, an event normally induced by epidermal growth factor (EGF). In this case, curcumin at the best concentration of $15 \mu \mathrm{g} / \mathrm{mL}$ is perfectly able to suppress RPEC proliferation and the positive effects of curcumin were assessed evaluating the proliferative membrane and the vitreous opacity which were significantly reduced in the group of patients treated with curcumin in comparison with the control group. ${ }^{67}$

\section{Principal Hereditary Tapeto-Retinal Degenerations}

The term Retinitis Pigmentosa (RP) (MIM\#268000) refers to a wide group of hereditary progressive and degenerative photoreceptor disorders leading to severe loss of vision or blindness. ${ }^{68}$
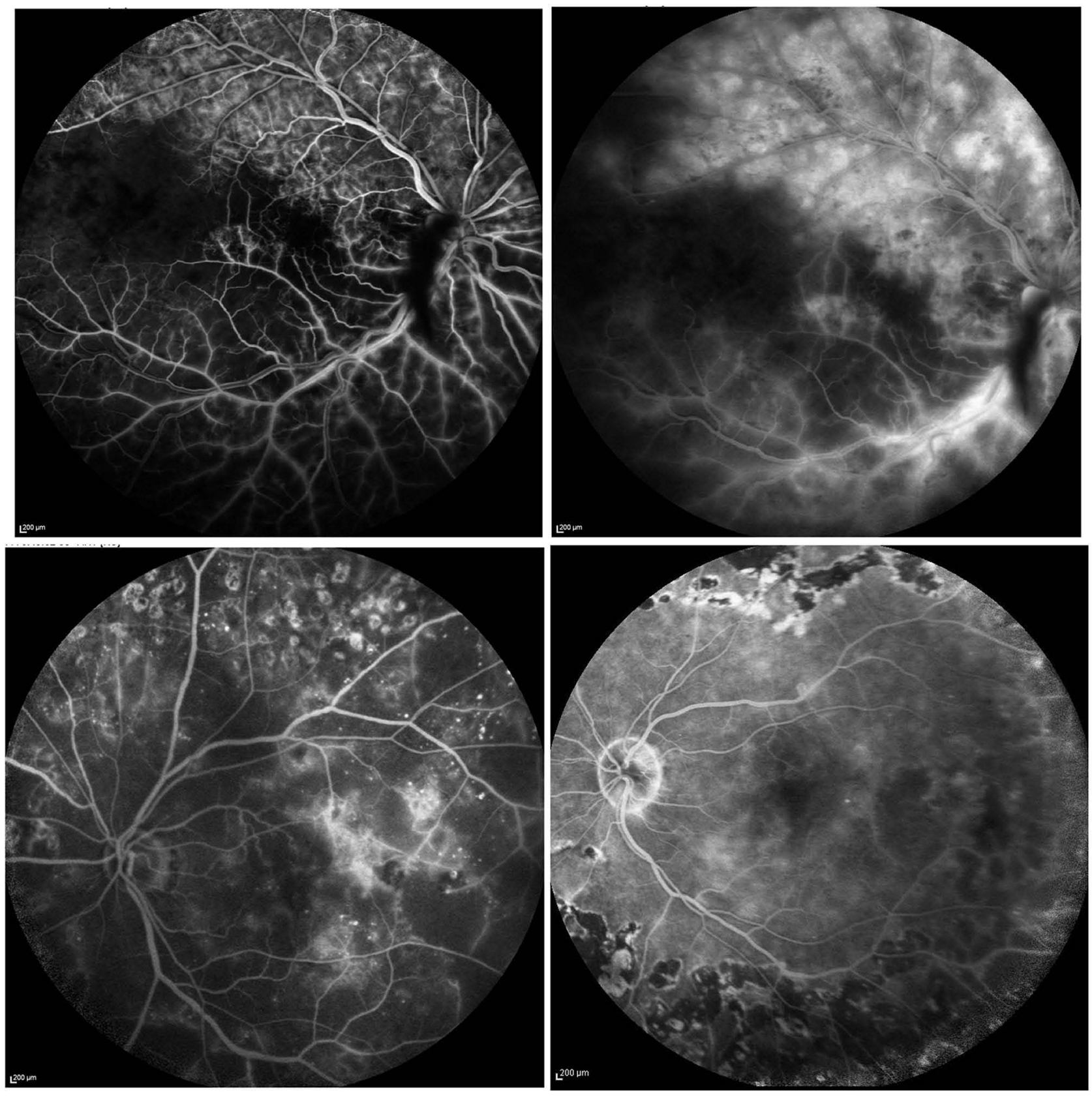

Figure 6 Panels of retinal angiography in central venous thrombosis with ischemic-edema and chorioretinal laser treatment. 
Commonly, the rods are the first type of photoreceptors being severely affected and only at a later time the cones are involved (Figure 7). The photoreceptors degeneration results in their apoptosis and, as a consequence, the retina undergoes progressive and irreversible atrophy. ${ }^{69}$ The RP prevalence is approximately 1:4000, affecting more than 1 million people worldwide. ${ }^{70}$

Many different genes are involved in the same disease phenotype (genetic heterogeneity); different diseases are able to determine mutations in each gene (allelic heterogeneity); different diseases are caused by different mutations in the same gene (phenotypic heterogeneity); different individuals, even among members of the same family, show different clinical effects, despite having the same gene mutation. ${ }^{71,72}$

Genetically, it is important to emphasize that the disease is transmitted in different ways with a different phenotypic presentation. For instance, X-linked patients, who represent approximately $5-15 \%$ of all cases, generally tend to show the most severe RP form, while, autosomal recessive RP subjects, which account for about $50-60 \%$ of all cases, and patients showing an autosomal dominant RP form, $30-40 \%$ of cases, have a better condition, particularly regarding the progression of the disease and the visual prognosis. Furthermore, they keep central vision intact for a longer period of time. ${ }^{69,73}$
Furthermore, RP exists both in syndromic and in nonsyndromic forms: specifically, the syndromic form of Retinitis Pigmentosa refers to those situations in which the RP is not isolated, but it is associated with a whole series of other conditions as developmental disorders or neurosensory abnormalities. Usher's syndrome is characterized by RP associated to congenital or early onset deafness, while in Bardet-Biedl syndrome (BBS), RP is accompanied by developmental delay, kidney disorders, obesity and polydactyly. Sometimes RP may also be related to mitochondrial or degenerative cerebellar disease. $^{71,74}$

Unfortunately, the disease has no curative treatment to date: new therapeutic options are being developed, as gene and cell therapy ${ }^{75-77}$ in order to replace defective cells or their functions. ${ }^{69}$

Different studies were conducted in order to establish curcumin effects in RP patients. Meanwhile it is necessary to observe that the photoreceptors contain a biological pigment named Rhodopsin: the majority of cases of autosomal dominant RP forms are due to the $\mathrm{P} 23 \mathrm{H}$ missense mutation of rhodopsin, leading to an anomalous rhodopsin misfolding which results in rhodopsin retaining the endoplasmic reticulum (ER). The insoluble aggregates formation of rhodopsin and their consecutive cell storage end in cell death. ${ }^{78-80}$ Khajavi et al discovered that curcumin
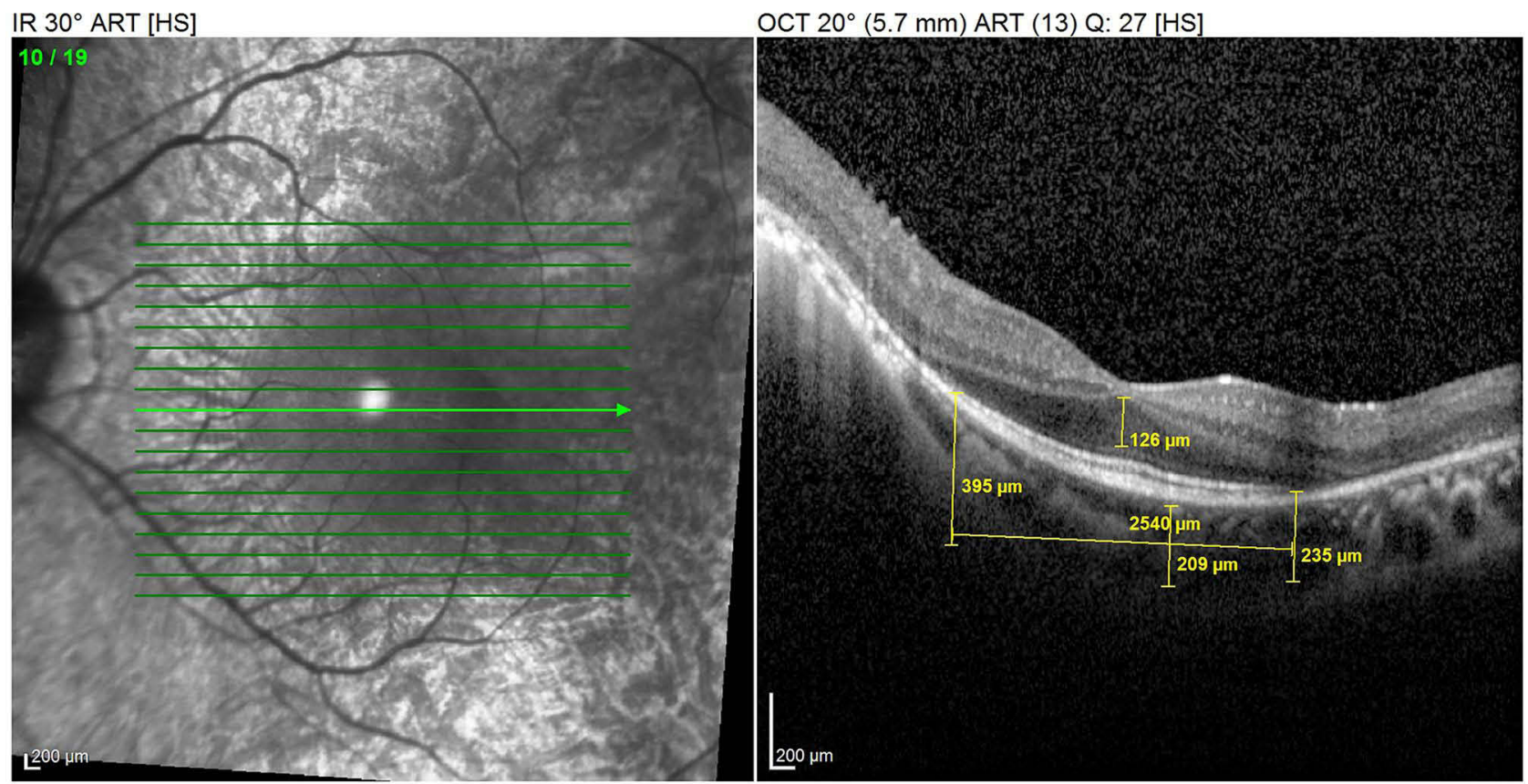

Figure 7 Spectral domain-optical coherence tomography in left eye of retinitis pigmentosa patient. It is possible to observe: an epiretinal membrane between the optic disc and the macula; loss of the photoreceptor layer beyond the fovea; increase of the central nuclear layer. 
prevents the ER retention of myelin protein aggregates, thus it may be a potential treatment for RP. ${ }^{81}$ These curcumin effects have been extensively studied in the transgenic rats affected by the $\mathrm{P} 23 \mathrm{H}$ rhodopsin mutation: the ones who received the curcumin treatment from postnatal day 30 (P30) to postnatal day 60 (P60) showed a significant improvement in terms of photoreceptor nuclei layer, photoreceptor outer and inner nuclear layer morphology. ${ }^{82}$ Specifically, they administered a $100 \mathrm{mg} /$ $\mathrm{kg}$ body weight dose of curcumin and observed that the latter is able to cross both the blood brain and blood retina barriers, when administered orally. P23H-R rats showed a retinal morphology amelioration with photoreceptor preservation. Moreover, an improvement in rod and cone specific genes levels of expression was assessed after curcumin administration. ${ }^{82}$ The curcumin effects against photoreceptor apoptosis, induced by the ROS generator methyl-N-nitrosourea (MNU), were also tested in a Sprague-Dawley rat model by Emoto et al. More in detail, three days prior to the MNU administration they injected doses of 100 or $200 \mathrm{mg} / \mathrm{kg}$ curcumin. A retinal damage reduction limited to central retina section after $200 \mathrm{mg} / \mathrm{kg}$ curcumin treatment was observed. Moreover, levels of 8-hydroxy-2'-deoxyguanosine as oxidative stress parameter were quantified, resulting in similar numbers to the control group, demonstrating an oxidative damage reduction. ${ }^{83}$

Lastly, curcumin prenatal protection in a Pro-23-His $(\mathrm{P} 23 \mathrm{H})$ rhodopsin mutation swine model was studied by Scott et al. They fed the sows $100 \mathrm{mg} / \mathrm{kg}$ bodyweight/day of curcumin up to two days prior to parturition. Then, Scott et al enucleated the embryos: the curcumin was able to prevent outer nuclear layer (ONL) and inner nuclear layer (INL) thinning. Furthermore, in line with Vasireddy, Scott et al highlighted the curcumin properties of preventing photoreceptor morphological changes. ${ }^{84}$

Best dystrophy (BD), also known as best vitelliform macular dystrophy (BVMD), is considered a form of macular degeneration typically presenting with a juvenile-onset and characterized by central visual loss. To date no therapy is available: in 2019 Lin et al picked up BD patient-derived dental pulp stromal cells, then induced them to de-differentiate into pluripotent stem cells (BD-iPSCs) and, finally, these cells were stimulated to differentiate into retinal pigment epithelial cells (BD-RPEC). The BD-RPEC showed a lower expression of both Bestrophin-1 (BEST1) and tight junction protein ZO-1 when compared with RPEC from control subjects. They observed that curcumin could significantly increase the mRNA expression levels of BEST1 gene in BD-iPSC-derived RPEC. Moreover, curcumin-loaded PLGA nanoparticles (Cur-NPs) could determine an augmentation in the expression of antioxidant enzymes with a decrease of ROS production. ${ }^{85}$

\section{Retinal and Choroidal Tumors}

Regarding the retinal and choroidal tumors, particularly the retinoblastoma, caused by the inactivation of the RB1 gene, a tumor suppressor gene, Li et al found that curcumin is able to inhibit RB cells' proliferation and migration as well as induce their apoptosis, even if curcumin effects on retinoblastoma $(\mathrm{Rb})$ are currently still unclear. ${ }^{86,87}$

More in detail, curcumin seems to determine the Janus kinase-signal transducer and activator of the transcription (JAK/STAT) signaling pathway inactivation, thanks to microRNA-99, due to its lack in microRNA-99a-silenced cells. Li et al studied these effects on SO-Rb50 and Y79 cells, retinoblastoma cell lines, where this compound downregulates the migratory capacities of the retinoblastoma cells. $^{86}$

\section{Curcumin Availability}

The primary limitation of curcumin is represented by its poor bioavailability, in fact only a minimal fraction of this substance can reach the blood stream in the form of a biologically active compound: therefore, to date, the greatest efforts are aimed at finding solutions to remedy this major restriction.

Extensive researches have demonstrated that high doses $(>3.6 \mathrm{~g} /$ day in humans) are needed to obtain any therapeutic effects, ${ }^{88}$ proved by many different studies: Wahlstrom and Blennow in 1978 reported a minimal curcumin level increase in the blood of Sprague-Dawley rats who received an oral administration of curcumin $(1 \mathrm{~g} / \mathrm{kg})$ as a consequence of its gut reduced absorption. ${ }^{89}$ Similarly, Yang et al referred to maximum serum curcumin levels of $0.36 \mu \mathrm{g} / \mathrm{mL}$ after $10 \mathrm{mg} / \mathrm{kg}$ of curcumin administered intravenously in rats. ${ }^{90}$ In order to enhance curcumin bioavailability, different approaches have been attempted, such as curcumin analogs and enhancers as well as delivery systems synthesis. All these attempts to improve the bioavailability of curcumin will now be examined in detail.

\section{Curcumin Analogs}

Numerous curcumin analogs have been synthetized to ameliorate the problems connected to curcumin molecular 
structure being responsible for its reduced disposability and mainly linked to the high reactivity of the $\beta$-diketone component of its structure. ${ }^{91}$

Wang et al developed the prodrug diphosphorylated curcumin (Cur-2p) followed by its subsequent enzymatic activation: they obtained a significant improvement in terms of molecular stability in the aqueous media. ${ }^{92}$ Similarly, Muangnoi et al compared the anti-oxidant properties of Cur prodrug curcumin diethyl disuccinate (CurDD) against curcumin in relation to oxidative stress induced in human ARPE-19 cells: they referred that both of them are able to exert a protective effect against oxidative damage by modulating different apoptotic signaling pathway as p44/42 (ERK) with consecutive downregulation of effector molecules $\mathrm{Bcl} 2$ and Bax, but, CurDD, a prodrug ester form of Cur, shows a better protective effect, thus it could be an interesting alternative therapeutic agent especially in the case of AMD. ${ }^{52}$

Other analogues of curcumin have been tested in different fields: for instance WZ35, a derivative of curcumin, shows a stronger antitumor activity than curcumin and, particularly, it is able to downregulate glycolysis. It has been studied as a promising gastric and breast cancer treatment, considering its ability to reduce tumoral cells proliferation, so it could even be a potential molecule to be considered in the treatment of retinal and choroidal tumors. ${ }^{93,94}$

\section{Curcumin Enhancers}

"Bioavailability enhancers" refer to the compounds able to improve the disposability of several substances: this is the case of piperine with regard to curcumin. Specifically, piperine, one of black pepper's components, when administered together with curcumin, is able to improve its oral bioavailability. ${ }^{95}$ Piperine performs this activity by decreasing curcumin hepatic and intestinal glucuronidation: ${ }^{32}$ Shoba et al observed that when curcumin was administered to rats alone in the dose $2 \mathrm{~g} / \mathrm{kg}$, the curcumin serum concentration was moderate, while, when administered in addition to piperine $20 \mathrm{mg} / \mathrm{kg}$, blood levels of curcumin increased. In humans, when given without piperine, curcumin serum concentration was undetectable Conversely, when given in association to piperine $20 \mathrm{mg}$, the increase in bioavailability was $2000 \%{ }^{96}$

\section{Curcumin Delivery Systems (Table I)}

Currently, researchers are trying to develop new curcumin carriers, exploiting the advances achieved in the field of nanotechnology: particularly, nanocarrier delivery systems consisting of nanoparticles, able to ameliorate some molecular properties such as bioavailability, solubility and stability in aqueous media. ${ }^{97}$

The first FDA approved nanocarriers were liposomes: ${ }^{98}$ they are spherical bilayer vesicles presenting in the center an aqueous nucleus. Commonly it presents a size approximately between $25-1000 \mathrm{~nm} \cdot{ }^{99,100}$

Liposomes, defined as single unilamellar vesicles (SUVs), large unilamellar vesicles (LUVs) and multilamellar vesicles (MLVs) depending on the molecular structure, show great advantages being both non-immunogenic and non-toxic.

More recently, Cur-loaded liposomal formulations have been realized: for instance, Shi et al synthetized curcuminloaded liposomes (Lipo-cur) consisting of cholesterol and lecithin. ${ }^{101}$ In this case the purpose was to use the curcumin radioprotective properties during irradiation in the irradiated mice. In addition to liposomes, the researchers developed polymeric micelles in the late $1980 \mathrm{~s} .{ }^{102}$ Structurally, the micelles consist of both hydrophilic and hydrophobic parts: numerous amphiphilic polymers were used for this purpose, such as poly(ethylene glycol) (PEG) and chitosan and polyvinyl pyrrolidone (PVP). As hydrophobic materials there are different possibilities, poly (lactic acid) (PLA), distearoyl phosphoethanolamine (DSPE), dioleoyl phosphatidylethanolamine (DOPE) and vitamin $\mathrm{E}$, and all of them can be used to realize the micelles core. In ophthalmology a kind of mixed micelle in situ gelling system of curcumin (Cur-MM-ISG) was prepared and showed the ability of remaining on the corneal surface. ${ }^{102-106}$,

Conversely, Alshamrani et al developed an aqueous nanomicellar drop formulation of curcumin (CUR-NMF) utilizing hydrogenated castor oil (HCO-40) and octoxynol40 (OC-40) in order to treat AMD. ${ }^{107}$

Davis et al used a non-ionic surfactant called $D-\alpha$ tocopherol polyethene glycol 1000 succinate (TPGS) that allows stable micelles formation when its concentrations are greater than $0.02 \% \mathrm{w} / \mathrm{w} 48$. TPGS was associated with a copolymer surfactant named Pluronic F127. This latter substance consists of hydrophobic and hydrophilic polyoxyethylene groups. They demonstrated that these nanoparticles were able to protect RCG soma in vivo against ocular hypertension, therefore showing a neuroprotective effect. ${ }^{108}$ Similarly, Duan et al developed an ion-sensitive curcumin-loaded Pluronic P123 (P123)/D-a-tocopheryl polyethylene glycol succinate (TPGS) mixed micelle 
Table I Types of Curcumin (Cur) Delivery Systems and Authors (in Bold)

\begin{tabular}{|c|c|}
\hline Types of Curcumin Delivery Systems and Structures. Models & Outcome and Authors \\
\hline $\begin{array}{l}\text { Liposomes: Nanocarriers composed of phospholipid bilayer with } \\
\text { particle size } 25-1000 \mathrm{~nm} \\
\text { Cur-loaded liposomes (Lipo-Cur) of lecithin and cholesterol. } \\
\text { Mice models. }\end{array}$ & $\begin{array}{l}\text { Radioprotective agent against radiation-induced mortality in mice } \\
\text { Sadeghi et al } 2019^{100} / \text { Shi et al } 2012^{101}\end{array}$ \\
\hline \multicolumn{2}{|l|}{$\begin{array}{l}\text { Polymeric micelles: Colloidal solutions composed of hydrophilic } \\
\text { shell and hydrophobic core which can load hydrophobic drugs }\end{array}$} \\
\hline $\begin{array}{l}\text { Mono methoxy poly (ethylene glycol)-poly ( } \varepsilon \text {-caprolactone) (mPEG-PCL } \\
\text { micelles) diblock copolymers. } \\
\text { Mice Models }\end{array}$ & $\begin{array}{l}\text { mPEG-PCL micelles increase CUR bioavailability } \\
\text { Kheiri Manjili et al } 2017^{103}\end{array}$ \\
\hline CUR loaded (D, L Poly lactic - Poly ethylenglycol) micelles (Cur/PLA-PEG) & $\begin{array}{l}\text { Solubility and anti-cancer activity of CUR improvement } \\
\text { Phan et al } 2016^{104}\end{array}$ \\
\hline $\begin{array}{l}\text { CUR loaded biodegradable self-assembled polymeric micelles (Cur-M). } \\
\text { Polymeric micelles encapsulating Cur. } \\
\text { In vitro }\end{array}$ & $\begin{array}{l}\text { Anti-tumor effect } \\
\text { Liu et al } 2013^{105}\end{array}$ \\
\hline $\begin{array}{l}\text { Poly (d,-l-lactide-co-glycolide)-b-poly(ethylene glycol)-b-poly(d,I-lactide-co } \\
\text {-glycolide) (PLGA-PEG-PLGA) copolymer. Cur-loaded PLGA-PEG-PLGA } \\
\text { micelles. }\end{array}$ & $\begin{array}{l}\text { CUR-loaded PLGA-PEG-PLGA micelles have a great bioavaibility } \\
\text { Song et al } 201 I^{111}\end{array}$ \\
\hline \multicolumn{2}{|l|}{$\begin{array}{l}\text { Polymeric Nanoparticles: Solid colloidal particles formed from } \\
\text { polymer materials }\end{array}$} \\
\hline $\begin{array}{l}\text { Cur encapsulated within the poly ( } \mathrm{N} \text {-isopropylacrylamide-co-methacrylic } \\
\text { acid) (NIPAAM-MAA). } \\
\text { MCF-7 breast cancer cell line }\end{array}$ & $\begin{array}{l}\text { MCF-7 cell line growth suppression } \\
\text { Zeighamian et al } 2016^{110}\end{array}$ \\
\hline $\begin{array}{l}\text { NanoCur synthesized using NIPAAM, vinylpyrrolidone (VP) and acrylic } \\
\text { acid (AA). } \\
\text { Brain tumor cell cultures }\end{array}$ & $\begin{array}{l}\text { Malignant brain tumor growth inhibition } \\
\qquad \text { Lim et al } 201 I^{111}\end{array}$ \\
\hline $\begin{array}{l}\text { Poly(lactic-co-glycolic acid) nanoparticles (PLGA-NPs) of Cur. } \\
\text { Mice models }\end{array}$ & $\begin{array}{l}\text { Higher release rate in the intestinal juice } \\
\qquad \text { Xie et al } 201 I^{1 / 2}\end{array}$ \\
\hline \multicolumn{2}{|l|}{ Mesoporous Silica Nanoparticles (MSNs) } \\
\hline $\begin{array}{l}\text { Cur loaded into MSN grafted of polyethyleneimine (PEI) and folic acid } \\
\text { (FA). } \\
\text { Human colon cancer cell line (LSI74T) }\end{array}$ & $\begin{array}{l}\text { Enhanced cellular uptake and cytotoxicity of MSN-PEI-FA. } \\
\qquad \text { Sun et al } 2019^{117}\end{array}$ \\
\hline $\begin{array}{l}\text { MSNs as drug molecule capsules synthesized and capped by chitosan } \\
\text { natural polymer. } \\
\text { U87MG glioblastoma cancer cell line }\end{array}$ & $\begin{array}{l}\text { Improvement of anticancer properties } \\
\text { Ahmadi Nasab et al } 2018^{1 / 8}\end{array}$ \\
\hline $\begin{array}{l}\text { Mesoporous silica material based drug delivery systems (S2, S4 and S6) } \\
\text { developed through the amine functionalization of KIT-6, MSU-2 and } \\
\text { MCM- } 4 \text { I followed by the loading of Cur. } \\
\text { Cancer cells }\end{array}$ & $\begin{array}{l}\text { Anti-cancer activity } \\
\text { Kotcherlakota et al } 2016^{119}\end{array}$ \\
\hline \multicolumn{2}{|l|}{ Protein-Based Nanocarriers } \\
\hline $\begin{array}{l}\text { Cur-loaded galactosylated (albumin) nanoparticles (Gal-BSA-Cur NPs). } \\
\text { HCC (HepG2) cells }\end{array}$ & $\begin{array}{l}\text { Suppression of nuclear factor } \kappa B-p 65 \text { (NF-kB-p65) expression in } \\
\text { HepG2 cell nucleus } \\
\text { Huang et al } 201 \mathbf{8}^{\mathbf{1 2 1}}\end{array}$ \\
\hline
\end{tabular}


Table I (Continued).

\begin{tabular}{|c|c|}
\hline Types of Curcumin Delivery Systems and Structures. Models & Outcome and Authors \\
\hline $\begin{array}{l}\text { Chemical conjugation of folate to the surface of Cur (CM)-loaded human } \\
\text { serum albumin nanoparticles (F-CM-HSANPs) } \\
\text { In vitro/ln vivo }\end{array}$ & $\begin{array}{l}\text { In vitro the CM-NPs, after conjugation with folate, determine a faster } \\
\text { release of CUR; in vivo improves antitumor activity } \\
\text { Song } Z \text {. et al } \mathbf{2 0 1 6 ^ { 1 2 2 }}\end{array}$ \\
\hline $\begin{array}{l}\text { Cur was physically entrapped and stabilized in silk hydrogel film. } \\
\text { Human bone marrow-derived mesenchymal stem cells (hBMSC) }\end{array}$ & $\begin{array}{l}\text { Effects on hBMSC proliferation and differentiation } \\
\qquad L i \text { et al } 2015^{123}\end{array}$ \\
\hline $\begin{array}{l}\text { Solid lipid nanoparticles (SLNs): Colloidal drug delivery system } \\
\text { composed of biodegradable solid lipids. Cur loaded on SLN } \\
\text { In vitro/ln vivo }\end{array}$ & $\begin{array}{l}\text { Tumor inhibition effect } \\
\text { Wang et al } 2013^{124}\end{array}$ \\
\hline $\begin{array}{l}\text { Cyclodextrins: Cyclic oligosaccharides with hydrophilic outer } \\
\text { surface and lipophilic cavity. } \\
\text { Beta-Cyclodextrin-Cur self-assembly. Cur encapsulation into the } \\
\text { cyclodextrin cavity. } \\
\text { Prostate cancer cells }\end{array}$ & $\begin{array}{l}\text { Improved therapeutic efficacy in prostate cancer cells } \\
\qquad \text { Yallapu et al } 2010^{125}\end{array}$ \\
\hline \multicolumn{2}{|l|}{$\begin{array}{l}\text { Nanogels: Drug delivery carries consisting of amphiphilic or } \\
\text { hydrophilic polymer networks }\end{array}$} \\
\hline $\begin{array}{l}\text { Interpenetrating polymeric network nanogels (IPN-NGs). Natural gelatin } \\
\text { biological protein macromolecules and poly (acrylamidoglycolic acid) } \\
\text { produced by free radical emulsion polymerization. } \\
\text { In vitro cultures of fibroblasts and a colorectal cancer cell line. }\end{array}$ & $\begin{array}{l}\text { IPN-NGs can be applied for colorectal cancer drug delivery } \\
\text { applications } \\
\text { Madhusudana } \text { Rao et al } 2015^{129}\end{array}$ \\
\hline $\begin{array}{l}\text { Cur conjugated as an ester to cholesteryl-hyaluronic acid (CHA) nanogel. } \\
\text { Murine mammary carcinoma cell line } 4 \mathrm{TI} \text { and human pancreatic } \\
\text { adenocarcinoma cells MiaPaCa-2 }\end{array}$ & $\begin{array}{l}\text { Tumor growth inhibition in human pancreatic adenocarcinoma } \\
\text { MiaPaCa-2 and arthotropic murine mammary carcinoma } 4 \mathrm{TI} \text { animal } \\
\text { models } \\
\text { Wei et al } 20 / 4^{130}\end{array}$ \\
\hline $\begin{array}{l}\text { Cur loaded chitin nanogels (CCNGs) } \\
\text { Human dermal fibroblast cells (HDF) and A375 (human melanoma) cell } \\
\text { lines }\end{array}$ & $\begin{array}{l}\text { Specific effects on melanoma } \\
\text { Mangalathillam et al } 2012^{131}\end{array}$ \\
\hline $\begin{array}{l}\text { Nanocrystals composed of } 100 \% \text { drug. Hyaluronic acid was carried } \\
\text { out on the surface of Cur } \\
\text { Mice models }\end{array}$ & $\begin{array}{l}\text { Anticancer effects in murine } 4 \mathrm{TI} \text { orthotopic breast cancer model } \\
\qquad \mathrm{Ji} \text { et al } 2020^{132}\end{array}$ \\
\hline
\end{tabular}

in situ gels (CUR-MM-ISGs) to guarantee a longer corneal permeability and retention time. ${ }^{109}$

Recently, one of the most curcumin promising delivery systems was represented by a new amphiphilic polymer polyvinyl caprolactam-polyvinyl acetate-polyethylene glycol graft copolymer (PVCL-PVA-PEG, Soluplus ${ }^{\circledR}$ ). This carrier consists of a hydrophilic part, represented by a polyethylene glycol (PEG) backbone, and a lipophilic, part expressed by vinylcaprolactam/vinyl acetate side chains as lipophilic structure. Therefore, curcumin is loaded onto PVCL-PVA-PEG nanomicelles, obtained thanks to a peculiar solvent evaporation/film hydration method. $^{96}$
Polymeric nanoparticles, solid colloidal particles, represent another strategy: several natural and synthetic polymers have been used to synthetize polymeric nanoparticles, such as chitosan (CS), PLGA, polyvinyl alcohol (PVA) and poly(butyl cyanoacrylate) (PBCA). ${ }^{96,110-112}$

Lou et al elaborated a complex in situ gel formulation consisting of curcumin-loaded albumin nanoparticles (CurBSA-NPs-Gel), a useful method by which it is possible to optimize curcumin bioavailability in aqueous humour as demonstrated both in rabbits and in human eyes. ${ }^{113}$

More recently porous materials, like mesoporous silica nanoparticles (MSNs), have also been used as curcumin 
vehicles, as reported by several studies, ${ }^{11-119}$ however, till now there is still no use of them in the field of ophthalmology.

In another study, some researchers incorporated alginate (AGT) with curcumin in order to develop a hydrogel based system CCI/AGT able to anchor RPEC in it. They observed that the system CCI/AGT could enhance RPEC regeneration in comparison with the pure AGT hydrogel. They proposed the use of this structure as a support for implantation of retinal tissue engineering. ${ }^{120}$

Due to their numerous properties as biocompatibility, biodegradability and non-immunogenicity, proteins became a valid option as nanoparticles for curcumin delivery, for instance bovine serum albumin (BSA), ovalbumin (OVA), human serum albumin (HSA), and silk fibroin (SF) nanoparticles. $^{121-123}$

In addition, solid lipid nanoparticles (SLNs) represent a colloidal drug delivery system characterized by the presence of biodegradable solid lipids. The curcumin is embedded in the lipid core of the SLN: this sort of encapsulation has been extensively used. ${ }^{124}$

It still worth remembering among curcumin delivery systems cyclodextrins, defined as cyclic oligosaccharides showing a peculiar structure of hollow truncated cone, nanogels and nanocrystals. Regarding cyclodextrins, in 2010 the use of cyclodextrins to guarantee an adequate administration of curcumin as an ophthalmic drop and it was discovered its utility in determining a seletine-induced cataract reduction in rats. ${ }^{125,126}$

Almost all of these last strategies have not yet been tested in the eye, therefore this will probably represent a future challenge for ophthalmologists. However, other approaches have been attempted: Zhang et al developed a biodegradable curcumin-loaded scleral plug for posterior ocular diseases treatment and they experimented with this system in rabbit's eyes, suggesting that in this way it is possible to maintain a high concentration of curcumin both in vitro and in vivo. ${ }^{127}$

A further possibility is represented by a curcuminphospholipid lecithin formulation, which seems to be able to ameliorate visual acuity and reduce ME in DR patients when administered as tablets twice a day, in addition to other strategies such as nanogels and nanocrystals. ${ }^{128-132}$

\section{Conclusions: What Prospects for the Future?}

To date, several studies suggest that oral treatment with curcumin is generally well tolerated in humans and, currently, side-effects have not been observed.
This condition may be explained considering that the curcumin dose used in clinical trials is lower than the dose reported in the in vitro/in vivo model, as well as the fact that this substance is normally subjected to extensive metabolism in intestine and liver with low plasma and tissue curcumin levels. $^{133}$

Some limitations regarding the use of curcumin are attributable, as previously mentioned, to the reduced bioavailability of this molecule and to its possible toxicity under specific conditions. For instance, curcumin seems to cause DNA alterations when used at concentrations similar to those necessary to exert its beneficial effects, both with in vitro and in vivo studies. Therefore, in this regard, some authors emphasize greater caution before considering curcumin as safe when its safety has not yet been definitely proven. ${ }^{133}$

Curcumin is a promising candidate as a retinal diseases therapy. The benefits are usually seen after a period of a few weeks of therapy, especially in chronic eye diseases such as diabetic retinopathy, maculopathy, ischemic retinopathy, glaucoma, etc. These effects are mainly due to its properties as an anti-oxidant and antiinflammatory molecule, though the precise mechanism underlying the beneficial effects of curcumin on retinal diseases still remains unclear. ${ }^{5}$

However, as discussed earlier, to date the main issue, only partially solved, concerns the possible strategies to be used in order to improve the bioavailability of the molecule. In this sense, many steps forward have been made, both in ophthalmology and in other fields: therefore, in the future it is expected that the strategies developed so far to allow curcumin to reach the target tissues in adequate concentrations could be ameliorated and, above all, large in vivo studies on humans are needed to demonstrate the total safety of these compounds and their effectiveness both in different retinal pathologies and, in general, in eye diseases.

\section{Disclosure}

The editorial support was funded by Eye Pharma S.p.A. Genova-Italy. The authors report no other conflicts of interest in this work.

\section{References}

1. López-Malo D, Villarón-Casares CA, Alarcón-Jiménez J, et al. Curcumin as a Therapeutic Option in Retinal Diseases. Antioxidants. 2020;9(1):48. doi:10.3390/antiox9010048

2. Rodríguez Castaño P, Parween S, Pandey AV. Bioactivity of Curcumin on the Cytochrome P450 Enzymes of the Steroidogenic Pathway. Int J Mol Sci. 2019;20(18):4606. doi:10.3390/ijms20184606. 
3. Mirzaee F, Hosseinzadeh L, Ashrafi-Kooshk MR, et al. Diverse Effects of Different "Protein-Based" Vehicles on the Stability and Bioavailability of Curcumin: spectroscopic Evaluation of the Antioxidant Activity and Cytotoxicity In Vitro. Protein Pept Lett. 2019;26(2):132-147. doi:10.2174/0929866525666181114152242.

4. Perrone D, Ardito F, Giannatempo G, et al. Biological and therapeutic activities, and anticancer properties of curcumin. Exp Ther Med. 2015;10(5):1615-1623. doi:10.3892/etm.2015.2749

5. Pescosolido N, Giannotti R, Plateroti AM, Pascarella A, Nebbioso M. Curcumin: therapeutical potential in ophthalmology. Planta Med. 2014;80(4):249-254. doi:10.1055/ s-0033-1351074

6. Deogade S, Ghate S. Curcumın: therapeutic applications in systemic and oral health. Int J Biol Pharm Res. 2015;6 (4):281-290.

7. Gupta SC, Kismali G, Aggarwal BB. Curcumin, a component of turmeric: from farm to pharmacy. Biofactors. 2013;39(1):2-13. doi:10.1002/biof.1079

8. Ammon HP, Wahl MA. Pharmacology of Curcuma longa. Planta Med. 1991;57(1):1-7. doi:10.1055/s-2006-960004

9. Takahashi $\mathrm{M}$, Ishiko $\mathrm{T}$, Kamohara $\mathrm{H}$, et al. Curcumin (1,7-bis (4-hydroxy-3-methoxyphenyl)-1,6-heptadiene-3,5-dione) blocks the chemotaxis of neutrophils by inhibiting signal transduction through IL-8 receptors. Mediators Inflamm. 2007;2007:10767. doi:10.1155/2007/10767

10. Lestari ML, Indrayanto G. Curcumin. Profiles Drug Subst Excip Relat Methodol. 2014;39:113-204. doi:10.1016/B978-0-12800173-8.00003-9

11. Mahady GB, Pendland SL, Yun G, Lu ZZ. Turmeric (Curcuma longa) and curcumin inhibit the growth of Helicobacter pylori, a group 1 carcinogen. Anticancer Res. 2002;22(6C):4179-4181.

12. Reddy DNK, Huang FY, Wang SP, Kumar R. Synergistic antioxidant and antibacterial activity of curcumin-C3 encapsulated chitosan nanoparticles. Curr Pharm Des. 2020;26(39):5021-5029. doi:10.2174/1381612826666200609164830

13. Anand P, Kunnumakkara AB, Newman RA, Aggarwal BB. Bioavailability of curcumin: problems and promises. Mol Pharm. 2007;4(6):807-818. doi:10.1021/mp700113r

14. Payton F, Sandusky P, Alworth WL. NMR study of the solution structure of curcumin. J Nat Prod. 2007;70(2):143-146. doi: $10.1021 / \mathrm{np} 060263 \mathrm{~s}$

15. Radomska-Leśniewska DM, Osiecka-Iwan A, Hyc A, Góźdź A, Dąbrowska AM, Skopiński P. Therapeutic potential of curcumin in eye diseases. Cent Eur J Immunol. 2019;44(2):181-189. doi:10.5114/ceji.2019.87070

16. Srinivas C, Prabhakaran KV. Haridra (curcuma longa) and its effect on abhisayanda (conjunctivitis). Anc Sci Life. 1989;8(34):279-282.

17. Awasthi S, Srivatava SK, Piper JT, Singhal SS, Chaubey M, Awasthi YC. Curcumin protects against 4-hydroxy-2-transnonenal-induced cataract formation in rat lenses. Am $\mathrm{J}$ Clin Nutr. 1996;64(5):761-766. doi:10.1093/ajcn/64.5.761.

18. Lal B, Kapoor AK, Asthana OP, et al. Efficacy of curcumin in the management of chronic anterior uveitis. Phytother Res. 1999;13 (4):318-322. doi:10.1002/(SICI)1099-1573(199906)13:4<318: AID-PTR445>3.0.CO;2-7

19. Wang LL, Sun Y, Huang K, Zheng L. Curcumin, a potential therapeutic candidate for retinal diseases. Mol Nutr Food Res. 2013;57(9):1557-1568. doi:10.1002/mnfr.201200718

20. Noorafshan A, Ashkani-Esfahani S. A review of therapeutic effects of curcumin. Curr Pharm Des. 2013;19(11):2032-2046.

21. Masuda T, Hidaka K, Shinohara A, Maekawa T, Takeda Y, Yamaguchi H. Chemical studies on antioxidant mechanism of curcuminoid: analysis of radical reaction products from curcumin. J Agric Food Chem. 1999;47(1):71-77. doi:10.1021/ jf9805348
22. Wang YJ, Pan MH, Cheng AL, et al. Stability of curcumin in buffer solutions and characterization of its degradation products. J Pharm Biomed Anal. 1997;15(12):1867-1876. doi:10.1016/ s0731-7085(96)02024-9

23. Guo LY, Cai XF, Lee JJ, et al. Comparison of suppressive effects of demethoxycurcumin and bisdemethoxycurcumin on expressions of inflammatory mediators in vitro and in vivo. Arch Pharm Res. 2008;31(4):490-496. doi:10.1007/s12272-0011183-8

24. Kocaadam B, Şanlier N. Curcumin, an active component of turmeric (Curcuma longa), and its effects on health. Crit Rev Food Sci Nutr. 2017;57(13):2889-2895. doi:10.1080/ 10408398.2015.1077195

25. Priyadarsini KI. The chemistry of curcumin: from extraction to therapeutic agent. Molecules. 2014;19(12):20091-20112. doi:10.3390/molecules191220091

26. Peddada KV, Brown A, Verma V, Nebbioso M. Therapeutic potential of curcumin in major retinal pathologies. Int Ophthalmol. 2019;39(3):725-734. doi:10.1007/s10792-0180845-y

27. Gupta SK, Kumar B, Nag TC, et al. Curcumin prevents experimental diabetic retinopathy in rats through its hypoglycemic, antioxidant, and anti-inflammatory mechanisms. $J$ Ocul Pharmacol Ther. 2011;27(2):123-130. doi:10.1089/ jop. 2010.0123

28. Singh S, Aggarwal BB. Activation of transcription factor NF-kappa B is suppressed by curcumin (diferuloylmethane) [corrected]. J Biol Chem. 1995;270(42):24995-25000. doi:10.1074/jbc.270.42.24995

29. Shishodia S, Sethi G, Aggarwal BB. Curcumin: getting back to the roots. Ann N Y Acad Sci. 2005;1056:206-217. doi:10.1196/ annals. 1352.010

30. Devasagayam TP, Sainis KB. Immune system and antioxidants, especially those derived from Indian medicinal plants. Indian J Exp Biol. 2002;40(6):639-655.

31. Amor S, Puentes F, Baker D, van der Valk P. Inflammation in neurodegenerative diseases. Immunology. 2010;129(2):147-309. doi:10.1111/j.1365-2567.2009.03225.x

32. Aggarwal BB, Harikumar KB. Potential therapeutic effects of curcumin, the anti-inflammatory agent, against neurodegenerative, cardiovascular, pulmonary, metabolic, autoimmune and neoplastic diseases. Int J Biochem Cell Biol. 2009;41(1):40-59. doi:10.1016/j.biocel.2008.06.010

33. Priyadarsini KI. Free radical reactions of curcumin in membrane models. Free Radic Biol Med. 1997;23(6):838-843. doi:10.1016/ s0891-5849(97)00026-9

34. Gorman AA, Hamblett I, Srinivasan VS, Wood PD. Curcuminderived transients: a pulsed laser and pulse radiolysis study. Photochem Photobiol. 1994;59(4):389-398. doi:10.1111/j.17511097.1994.tb05053.x

35. Sugiyama $\mathrm{Y}$, Kawakishi $\mathrm{S}$, Osawa $\mathrm{T}$. Involvement of the beta-diketone moiety in the antioxidative mechanism of tetrahydrocurcumin. Biochem Pharmacol. 1996;52(4):519-525. doi:10.1016/0006-2952(96)00302-4

36. Jovanovic SV, Boone CW, Steenken S, Trinoga M, Kaskey RB. How curcumin works preferentially with water soluble antioxidants. $J$ Am Chem Soc. 2001;123(13):3064-3068. doi: $10.1021 / \mathrm{ja} 003823 \mathrm{x}$

37. Litwinienko G, Ingold KU. Abnormal solvent effects on hydrogen atom abstraction. 2. Resolution of the curcumin antioxidant controversy. The role of sequential proton loss electron transfer. J Org Chem. 2004;69(18):5888-5896. doi:10.1021/jo049254j

38. Ushio-Fukai M, Alexander RW. Reactive oxygen species as mediators of angiogenesis signaling: role of $\mathrm{NAD}(\mathrm{P}) \mathrm{H}$ oxidase. Mol Cell Biochem. 2004;264(1-2):85-97. doi:10.1023/B:MCBI.0000044378. 09409.b5 
39. Chen WH, Chen Y, Cui GH. Effects of TNF-alpha and curcumin on the expression of VEGF in Raji and U937 cells and on angiogenesis in ECV304 cells. Chin Med J. 2005;118 (24):2052-2057.

40. Millanta F, Citi S, Della Santa D, Porciani M, Poli A. COX-2 expression in canine and feline invasive mammary carcinomas: correlation with clinicopathological features and prognostic molecular markers. Breast Cancer Res Treat. 2006;98(1):115-120. doi:10.1007/s10549-005-9138-z.

41. Yoysungnoen P, Wirachwong $\mathrm{P}$, Changtam C, Suksamrarn A, Patumraj S. Anti-cancer and anti-angiogenic effects of curcumin and tetrahydrocurcumin on implanted hepatocellular carcinoma in nude mice. World J Gastroenterol. 2008;14(13):2003-2009. doi:10.3748/wjg. 14.2003

42. Li L, Braiteh FS, Kurzrock R. Liposome-encapsulated curcumin: in vitro and in vivo effects on proliferation, apoptosis, signaling, and angiogenesis. Cancer. 2005;104(6):1322-1331. doi:10.1002/ cncr. 21300

43. Ravindran J, Prasad S, Aggarwal BB. Curcumin and cancer cells: how many ways can curry kill tumor cells selectively? AAPS $J$. 2009;11(3):495-510. doi:10.1208/s12248-009-9128-x

44. Maheshwari RK, Singh AK, Gaddipati J, Srimal RC. Multiple biological activities of curcumin: a short review. Life Sci. 2006;78 (18):2081-2087. doi:10.1016/j.lfs.2005.12.007

45. Devassy JG, Nwachukwu ID, Jones PJ. Curcumin and cancer: barriers to obtaining a health claim. Nutr Rev. 2015;73 (3):155-165. doi:10.1093/nutrit/nuu064

46. Sidhu GS, Singh AK, Thaloor D, et al. Enhancement of wound healing by curcumin in animals. Wound Repair Regen. 1998;6 (2):167-177. doi:10.1046/j.1524-475x.1998.60211.x

47. Munia I, Gafray L, Bringer MA, et al. Cytoprotective effects of natural highly bio-available vegetable derivatives on human-derived retinal cells. Nutrients. 2020;12(3):879. doi:10.3390/nu12030879

48. Lal B, Kapoor AK, Asthana OP, et al. Efficacy of curcumin in the management of chronic anterior uveitis. Phytother Res. 1999;13 (4):318-322. doi:10.1002/(SICI)1099-1573(199906)13:

49. Allegri P, Mastromarino A, Neri P. Management of chronic anterior uveitis relapses: efficacy of oral phospholipidic curcumin treatment. Long-Term Follow-Up Clin Ophthalmol. 2010;4:1201-1206. doi:10.2147/OPTH.S13271.

50. Miserocchi E, Giuffrè C, Cicinelli MV, et al. Oral phospholipidic curcumin in juvenile idiopathic arthritis-associated uveitis. Eur J Ophthalmol. 2019:1120672119892804. doi:10.1177/ 1120672119892804

51. Mandal MN, Patlolla JM, Zheng L, et al. Curcumin protects retinal cells from light-and oxidant stress-induced cell death Free Radic Biol Med. 2009;46(5):672-679. doi:10.1016/j. freeradbiomed.2008.12.006

52. Muangnoi C, Sharif U. Protective effects of curcumin ester prodrug, curcumin diethyl disuccinate against $\mathrm{H} 2 \mathrm{O} 2$-induced oxidative stress in human retinal pigment epithelial cells: potential therapeutic avenues for age-related macular degeneration. Int J Mol Sci. 2019;20(13):3367. doi:10.3390/ijms20133367

53. Ciulla TA, Amador AG, Zinman B. Diabetic retinopathy and diabetic macular edema: pathophysiology, screening, and novel therapies. Diabetes Care. 2003;26(9):2653-2664. doi:10.2337/ diacare.26.9.2653

54. Cheung N, Wong IY, Wong TY. Ocular anti-VEGF therapy for diabetic retinopathy: overview of clinical efficacy and evolving applications. Diabetes Care. 2014;37(4):900-905. doi:10.2337/ dc13-1990

55. Kowluru RA, Kanwar M. Effects of curcumin on retinal oxidative stress and inflammation in diabetes. Nutr Metab. 2007;4:8. doi:10.1186/1743-7075-4-8
56. Chiu J, Xu BY, Chen S, Feng B, Chakrabarti S. Oxidative stress-induced, poly(ADP-ribose) polymerase-dependent upregulation of ET-1 expression in chronic diabetic complications. Can J Physiol Pharmacol. 2008;86(6):365-372. doi:10.1139/Y08-033

57. Premanand C, Rema M, Sameer MZ, Sujatha M, Balasubramanyam M. Effect of curcumin on proliferation of human retinal endothelial cells under in vitro conditions. Invest Ophthalmol Vis Sci. 2006;47(5):2179-2184. doi:10.1167/iovs.050580

58. Wang $\mathrm{C}$, Nie $\mathrm{H}$, Li K, et al. Curcumin inhibits HMGB1 releasing and attenuates concanavalin A-induced hepatitis in mice. Eur $J \quad$ Pharmacol. 2012;697(1-3):152-157. doi:10.1016/j. ejphar.2012.09.050

59. Kumar PA, Haseeb A, Suryanarayana P, Ehtesham NZ, Reddy GB. Elevated expression of alphaA- and alphaB-crystallins in streptozotocin-induced diabetic rat. Arch Biochem Biophys. 2005;444(2):77-83. doi:10.1016/j. abb.2005.09.021

60. Mrudula T, Suryanarayana P, Srinivas PNBS, Reddy GB. Effect of curcumin on hyperglycemia-induced vascular endothelial growth factor expression in streptozotocin-induced diabetic rat retina. Biochem Biophys Res Commun. 2007;361(2):528-532. doi:10.1016/j.bbrc.2007.07.059

61. Khimmaktong W, Petpiboolthai H, Sriya P, Anupunpisit V. Effects of curcumin on restoration and improvement of microvasculature characteristic in diabetic rat's choroid of eye. $J$ Med Assoc Thai. 2014;97(Supp1 2):S39-46.

62. Ran Z, Zhang Y, Wen X, Ma J. Curcumin inhibits high glucose induced inflammatory injury in human retinal pigment epithelial cells through the ROS PI3K/AKT/mTOR signaling pathway. Mol Med Rep. 2019;19(2):1024-1031. doi:10.3892/mmr.2018.9749

63. Mazzolani F, Togni S. Oral administration of a curcumin-phospholipid delivery system for the treatment of central serous chorioretinopathy: a 12-month follow-up study. Clin Ophthalmol. 2013;7:939-945. doi:10.2147/OPTH.S45820

64. Ferrara M, Allegrini D, Sorrentino T, et al. Curcumin-based treatment for macular edema from uncommon etiologies: efficacy and safety assessment. J Med Food. 2020;23(8):834-840. doi:10.1089/jmf.2019.0241

65. Wang L, Li C, Guo H, Kern TS, Huang K, Zheng L. Curcumin inhibits neuronal and vascular degeneration in retina after ischemia and reperfusion injury. PLoS One. 2011;6(8):e23194. doi:10.1371/journal.pone.0023194

66. Wang S, Ye Q, Tu J, Zhang M, Ji B. Curcumin protects against hypertension aggravated retinal ischemia/reperfusion in a rat stroke model. Clin Exp Hypertens. 2017;39(8):711-717. doi:10.1080/10641963.2017.1313854

67. Ren YX, Ma JX, Zhao F, An JB, Geng YX, Liu LY. Effects of curcumin on epidermal growth factor in proliferative vitreoretinopathy. Cell Physiol Biochem. 2018;47(5):2136-2146. doi:10.1159/000491525

68. Khan MI, Kersten FF, Azam M, et al. CLRN1 mutations cause nonsyndromic retinitis pigmentosa. Ophthalmology. 2011;118 (7):1444-1448. doi:10.1016/j.ophtha.2010.10.047

69. Limoli PG, Vingolo EM, Limoli C, Nebbioso M. Antioxidant and biological properties of mesenchymal cells used for therapy in retinitis pigmentosa. Antioxidants. 2020;9(10):E983. doi:10.3390/ antiox9100983

70. Pagon RA. Retinitis pigmentosa. Surv Ophthalmol. 1988;33 (3):137-177. doi:10.1016/0039-6257(88)90085-9

71. Daiger SP, Sullivan LS, Bowne SJ. Genes and mutations causing retinitis pigmentosa. Clin Genet. 2013;84(2):132-141. doi:10.1111/cge. 12203

72. Hartong DT, Berson EL, Dryja TP. Retinitis pigmentosa. Lancet. 2006;368(9549):1795-1809. doi:10.1016/S0140-6736(06) 69740-7 
73. Hamel C. Retinitis pigmentosa. Orphanet J Rare Dis. 2006;1 (1):40. doi:10.1186/1750-1172-1-40

74. Grover S, Fishman GA, Alexander KR, Anderson RJ, Derlacki DJ. Visual acuity impairment in patients with retinitis pigmentosa. Ophthalmology. 1996;103(10):1593-1600. doi:10.1016/s0161-6420(96)30458-2

75. McCulloch DL, Marmor MF, Brigell MG, et al. ISCEV Standard for full-field clinical electroretinography (2015 update). Doc Ophthalmol. 2015;130(1):1-12. doi:10.1007/s10633-014-9473-7

76. Liu G, Liu X, Li H, Du Q, Wang F. Optical coherence tomographic analysis of retina in retinitis pigmentosa patients. Ophthalmic Res. 2016;56(3):111-122. doi:10.1159/000445063

77. Smith LE. Bone marrow-derived stem cells preserve cone vision in retinitis pigmentosa. $J$ Clin Invest. 2004;114(6):755-757. doi:10.1172/JCI22930

78. Dryja TP, Li T. Molecular genetics of retinitis pigmentosa. Hum Mol Genet. 1995;4:1739-1743. doi:10.1093/hmg/4.suppl_1.1739

79. Illing ME, Rajan RS, Bence NF, Kopito RR. A rhodopsin mutant linked to autosomal dominant retinitis pigmentosa is prone to aggregate and interacts with the ubiquitin proteasome system. $J$ Biol Chem. 2002;277:34150-34160. doi:10.1074/jbc. M204955200

80. Saliba RS, Munro PM, Luthert PJ, Cheetham ME. The cellular fate of mutant rhodopsin: quality control, degradation and aggresome formation. J Cell Sci. 2002;115(Pt 14):2907-2918. doi:10.1242/jcs.115.14.2907

81. Khajavi M, Shiga K, Wiszniewski W, et al. Oral curcumin mitigates the clinical and neuropathologic phenotype of the trembler-J mouse: a potential therapy for inherited neuropathy. Am J Hum Genet. 2007;81(3):438-453. doi:10.1086/519926

82. Vasireddy V, Chavali VR, Joseph VT, et al. Rescue of photoreceptor degeneration by curcumin in transgenic rats with $\mathrm{P} 23 \mathrm{H}$ rhodopsin mutation. PLoS One. 2011;6(6):e21193. doi:10.1371/ journal.pone.0021193

83. Emoto Y, Yoshizawa K, Uehara N, et al. Curcumin suppresses $\mathrm{N}$-methyl-N-nitrosourea-induced photoreceptor apoptosis in Sprague-Dawley rats. Vivo. 2013;27(5):583-590.

84. Scott PA, Kaplan HJ, McCall MA. Prenatal exposure to curcumin protects rod photoreceptors in a transgenic Pro23His Swine model of retinitis pigmentosa. Transl Vis Sci Technol. 2015;4 (5):5. doi:10.1167/tvst.4.5.5

85. Lin TC, Lin YY, Hsu CC, et al. Nanomedicine-based curcumin approach improved ros damage in best dystrophy-specific induced pluripotent stem cells. Cell Transplant. 2019;28(11):1345-1357. doi:10.1177/0963689719860130

86. Li Y, Sun W, Han N, Zou Y, Yin D. Curcumin inhibits proliferation, migration, invasion and promotes apoptosis of retinoblastoma cell lines through modulation of miR-99a and JAK/STAT pathway. BMC Cancer. 2018;18(1):1230. doi:10.1186/s12885018-5130-y

87. Bar-Sela G, Epelbaum R, Schaffer M. Curcumin as an anti-cancer agent: review of the gap between basic and clinical applications. Curr Med Chem. 2010;17(3):190-197. doi:10.2174/ 092986710790149738

88. Sharma RA, Steward WP, Gescher AJ. Pharmacokinetics and pharmacodynamics of curcumin. Adv Exp Med Biol. 2007;595:453-470. doi:10.1007/978-0-387-46401-5_20

89. Wahlström B, Blennow G. A study on the fate of curcumin in the rat. Acta Pharmacol Toxicol. 1978;43(2):86-92. doi:10.1111/ j.1600-0773.1978.tb02240.x

90. Yang KY, Lin LC, Tseng TY, Wang SC, Tsai TH. Oral bioavailability of curcumin in rat and the herbal analysis from Curcuma longa by LC-MS/MS. J Chromatogr B Analyt Technol Biomed Life $\quad$ Sci. $\quad 2007 ; 853(1-2): 183-189 . \quad$ doi:10.1016/j. jchromb.2007.03.010
91. Noureddin SA, El-Shishtawy RM, Al-Footy KO. Curcumin analogues and their hybrid molecules as multifunctional drugs. Eur J Med Chem. 2019;182:111631. doi:10.1016/j. ejmech.2019.111631

92. Wang J, Xiong T, Zhou J, et al. Enzymatic formation of curcumin in vitro and in vivo. Nano Res. 2018;11:3453-3461. doi:10.1007/ s12274-018-1994-z

93. Chen Y, Lu Y, Lee RJ, Xiang G. Nano encapsulated curcumin: and its potential for biomedical applications. Int J Nanomedicine. 2020;15:3099-3120. doi:10.2147/IJN.S210320

94. Wang L, Wang C, Tao Z, et al. Curcumin derivative WZ35 inhibits tumor cell growth via ROS-YAP-JNK signaling pathway in breast cancer. J Exp Clin Cancer Res. 2019;38(1):460. doi:10.1186/s13046-019-1424-4

95. Ohori H, Yamakoshi H, Tomizawa M, et al. Synthesis and biological analysis of new curcumin analogues bearing an enhanced potential for the medicinal treatment of cancer. Mol Cancer Ther. 2006;5(10):2563-2571. doi:10.1158/1535-7163.MCT-06-0174

96. Shoba G, Joy D, Joseph T, Majeed M, Rajendran R, Srinivas PS. Influence of piperine on the pharmacokinetics of curcumin in animals and human volunteers. Planta Med. 1998;64 (4):353-356. doi:10.1055/s-2006-957450

97. Li M, Xin M, Guo C, Lin G, Wu X. New nanomicelle curcumin formulation for ocular delivery: improved stability, solubility, and ocular anti-inflammatory treatment. Drug Dev Ind Pharm. 2017;43(11):1846-1857. doi:10.1080/03639045.2017.1349787

98. Barenholz Y. Doxil ${ }^{\mathbb{B}}$-the first FDA-approved nano-drug: lessons learned. J Control Release. 2012;160(2):117-134. doi:10.1016/j. jconrel.2012.03.020

99. Zhang W, Ma W, Zhang J, Song X, Sun W, Fan Y. The immunoregulatory activities of astragalus polysaccharide liposome on macrophages and dendritic cells. Int J Biol Macromol. 2017;105 (Pt 1):852-861. doi:10.1016/j.ijbiomac.2017.07.108

100. Sadeghi R, Razzaghdoust A, Bakhshandeh M, Nasirinezhad F, Mofid B. Nanocurcumin as a radioprotective agent against radiation-induced mortality in mice. Nanomed J. 2019;6 (1):43-49.

101. Shi HS, Gao X, Li D, et al. A systemic administration of liposomal curcumin inhibits radiation pneumonitis and sensitizes lung carcinoma to radiation. Int J Nanomedicine. 2012;7:2601-2611. doi:10.2147/IJN.S31439

102. Cabral H, Kataoka K. Progress of drug-loaded polymeric micelles into clinical studies. J Control Release. 2014;190:465-476. doi:10.1016/j.jconrel.2014.06.042

103. Kheiri Manjili H, Ghasemi P, Malvandi H, Mousavi MS, Attari E, Danafar H. Pharmacokinetics and in vivo delivery of curcumin by copolymeric mPEG-PCL micelles. Eur J Pharm Biopharm. 2017;116:17-30. doi:10.1016/j.ejpb.2016.10.003

104. Phan QT, Le MH, Le TT, Tran TH, Xuan PN, Ha PT. Characteristics and cytotoxicity of folate-modified curcumin-loaded PLA-PEG micellar nano systems with various PLA:PEG ratios. Int $J$ Pharm. 2016;507(1-2):32-40. doi:10.1016/j.ijpharm.2016.05.003

105. Liu L, Sun L, Wu Q, et al. Curcumin loaded polymeric micelles inhibit breast tumor growth and spontaneous pulmonary metastasis. Int $J$ Pharm. 2013;443(1-2):175-182. doi:10.1016/j. ijpharm.2012.12.032

106. Song Z, Feng R, Sun M, et al. Curcumin-loaded PLGA-PEGPLGA triblock copolymeric micelles: preparation, pharmacokinetics and distribution in vivo. J Colloid Interface Sci. 2011;354 (1):116-123. doi:10.1016/j.jcis.2010.10.024

107. Alshamrani M, Sikder S, Coulibaly F, Mandal A, Pal D, Mitra AK. Self-assembling topical nanomicellar formulation to improve curcumin absorption across ocular tissues. AAPS PharmSciTech. 2019;20(7):254. doi:10.1208/s12249-019-1404-1 
108. Davis BM, Pahlitzsch M, Guo L, et al. Topical curcumin nanocarriers are neuroprotective in eye disease. Sci Rep. 2018;8 (1):11066. doi:10.1038/s41598-018-29393-8

109. Duan Y, Cai X, Du H, Zhai G. Novel in situ gel systems based on P123/TPGS mixed micelles and gellan gum for ophthalmic delivery of curcumin. Colloids Surf $B$ Biointerfaces. 2015;128:322-330. doi:10.1016/j.colsurfb.2015.02.007

110. Zeighamian V, Darabi M, Akbarzadeh A, et al. PNIPAAm-MAA nanoparticles as delivery vehicles for curcumin against MCF-7 breast cancer cells. Artif Cells Nanomed Biotechnol. 2016;44 (2):735-742. doi:10.3109/21691401.2014.982803

111. Lim KJ, Bisht S, Bar EE, Maitra A, Eberhart CG. A polymeric nanoparticle formulation of curcumin inhibits growth, clonogenicity and stem-like fraction in malignant brain tumors. Cancer Biol Ther. 2011;11(5):464-473. doi:10.4161/cbt.11.5.14410

112. Xie X, Tao Q, Zou Y, et al. PLGA nanoparticles improve the oral bioavailability of curcumin in rats: characterizations and mechanisms. J Agric Food Chem. 2011;59(17):9280-9289. doi:10.1021/jf202135j

113. Lou J, Hu W, Tian R, et al. Optimization and evaluation of a thermoresponsive ophthalmic in situ gel containing curcumin-loaded albumin nanoparticles. Int $J$ Nanomedicine. 2014;9:2517-2525. doi:10.2147/IJN.S60270

114. Li Z, Barnes JC, Bosoy A, Stoddart JF, Zink JI. Mesoporous silica nanoparticles in biomedical applications. Chem Soc Rev. 2012;41 (7):2590-2605. doi:10.1039/c1cs15246g

115. Trewyn BG, Giri S, Slowing II, Lin VS. Mesoporous silica nanoparticle based controlled release, drug delivery, and biosensor systems. Chem Commun (Camb). 2007;1(31):3236-3245. doi:10.1039/b701744h

116. Wu SH, Mou CY, Lin HP. Synthesis of mesoporous silica nanoparticles. Chem Soc Rev. 2013;42(9):3862-3875. doi:10.1039/c3cs35405a

117. Sun X, Wang N, Yang LY, Ouyang XK, Huang F. Folic acid and PEI modified mesoporous silica for targeted delivery of curcumin. Pharmaceutics. 2019;11(9):430. doi:10.3390/ pharmaceutics 11090430

118. Ahmadi Nasab N, Hassani Kumleh H, Beygzadeh M, Teimourian S, Kazemzad M. Delivery of curcumin by a $\mathrm{pH}$-responsive chitosan mesoporous silica nanoparticles for cancer treatment. Artif Cells Nanomed Biotechnol. 2018;46(1):75-81. doi:10.1080/21691401.2017.1290648

119. Kotcherlakota R, Barui AK, Prashar S, et al. Curcumin loaded mesoporous silica: an effective drug delivery system for cancer treatment. Biomater Sci. 2016;4(3):448-459. doi:10.1039/ c5bm00552c

120. Park JH, Shin EY, Shin ME, et al. Enhanced retinal pigment epithelium (RPE) regeneration using curcumin/alginate hydrogels: in vitro evaluation. Int $J$ Biol Macromol. 2018;117:546-552. doi:10.1016/j.ijbiomac.2018.05.127

121. Huang Y, Hu L, Huang S, et al. Curcumin-loaded galactosylated BSA nanoparticles as targeted drug delivery carriers inhibit hepatocellular carcinoma cell proliferation and migration. Int $J$ Nanomedicine. 2018;13:8309-8323. doi:10.2147/IJN. S184379

Clinical Ophthalmology

\section{Publish your work in this journal}

Clinical Ophthalmology is an international, peer-reviewed journal covering all subspecialties within ophthalmology. Key topics include: Optometry; Visual science; Pharmacology and drug therapy in eye diseases; Basic Sciences; Primary and Secondary eye care; Patient Safety and Quality of Care Improvements. This journal is indexed on PubMed

Submit your manuscript here: https://www.dovepress.com/clinical-ophthalmology-journal
122. Song Z, Lu Y, Zhang X, Wang H, Han J, Dong C. Novel curcumin-loaded human serum albumin nanoparticles surface functionalized with folate: characterization and in vitro/vivo evaluation. Drug Des Devel Ther. 2016;10:2643-2649. doi:10.2147/DDDT.S112039

123. Li C, Luo T, Zheng Z, Murphy AR, Wang X, Kaplan DL. Curcumin-functionalized silk materials for enhancing adipogenic differentiation of bone marrow-derived human mesenchymal stem cells. Acta Biomater. 2015;11:222-232. doi:10.1016/j. actbio.2014.08.009

124. Wang P, Zhang L, Peng H, Li Y, Xiong J, Xu Z. The formulation and delivery of curcumin with solid lipid nanoparticles for the treatment of on non-small cell lung cancer both in vitro and in vivo. Mater Sci Eng C Mater Biol Appl. 2013;33(8):4802-4808. doi:10.1016/j.msec.2013.07.047

125. Yallapu MM, Jaggi M, Chauhan SC. beta-Cyclodextrin-curcumin self-assembly enhances curcumin delivery in prostate cancer cells. Colloids Surf B Biointerfaces. 2010;79(1):113-125. doi:10.1016/j.colsurfb.2010.03.039

126. Chaniyilparampu RN, Nair AK, Parthasarathy $\mathrm{K}$, et al. Curcuminoids and its metabolites for the application in allergic ocular/nasal conditions. Int Publication Number. 2010;25: WO2010109482A2.

127. Zhang J, Sun H, Zhou N, Zhang B, Ma J. Preparation and evaluation of biodegradable scleral plug containing curcumin in rabbit eye. Curr Eye Res. 2017;42(12):1597-1603. doi:10.1080/ 02713683.2016.1242753

128. Steigerwalt R, Nebbioso M, Appendino G, et al. Meriva ${ }^{\circledR}$, a lecithinized curcumin delivery system, in diabetic microangiopathy and retinopathy. Panminerva Med. 2012;54(1 Suppl 4):11-16

129. Madhusudana Rao K, Krishna Rao KS, Ramanjaneyulu G, Ha CS. Curcumin encapsulated $\mathrm{pH}$ sensitive gelatin based interpenetrating polymeric network nanogels for anti cancer drug delivery. Int $J$ Pharm. 2015;478(2):788-795. doi:10.1016/j. ijpharm.2014.12.001

130. Wei X, Senanayake TH, Bohling A, Vinogradov SV. Targeted nanogel conjugate for improved stability and cellular permeability of curcumin: synthesis, pharmacokinetics, and tumor growth inhibition. Mol Pharm. 2014;11(9):3112-3122. doi:10.1021/ mp500290f

131. Mangalathillam S, Rejinold NS, Nair A, Lakshmanan VK, Nair SV, Jayakumar R. Curcumin loaded chitin nanogels for skin cancer treatment via the transdermal route. Nanoscale. 2012;4(1):239-250. doi:10.1039/c1nr11271f

132. Ji P, Wang L, Chen Y, Wang S, Wu Z, Qi X. Hyaluronic acid hydrophilic surface rehabilitating curcumin nanocrystals for targeted breast cancer treatment with prolonged biodistribution. Biomater Sci. 2020;8(1):462-472. doi:10.1039/c9bm01605h

133. Burgos-Morón E, Calderón-Montaño JM, Salvador J, Robles A, López-Lázaro M. The dark side of curcumin. Int $J$ Cancer. 2010;126(7):1771-1775. doi:10.1002/ijc.24967
Central and CAS, and is the official journal of The Society of Clinical Ophthalmology (SCO). The manuscript management system is completely online and includes a very quick and fair peer-review system, which is all easy to use. Visit http://www.dovepress.com/ testimonials.php to read real quotes from published authors. 